\title{
Virtual reality in research and rehabilitation of gait and balance in Parkinson disease
}

Colleen G Canning, ${ }^{* 1}$ Natalie E Allen, ${ }^{1}$ Evelien Nackaerts, ${ }^{2}$ Serene S Paul, ${ }^{1}$ Alice Nieuwboer, ${ }^{2}$ Moran Gilat ${ }^{2}$

${ }^{1}$ Discipline of Physiotherapy, Faculty of Medicine and Health, University of Sydney

${ }^{2}$ Research Group for Neurorehabilitation (eNRGy), Department of Rehabilitation Sciences, KU Leuven

*email : colleen.canning@sydney.edu.au

\begin{abstract}
Virtual reality (VR) technology has emerged as a promising tool for studying and rehabilitating gait and balance impairments in people with Parkinson disease (PD) as it allows users to be engaged in an enriched and highly individualized complex environment. This Review examines the rationale and evidence for using VR in the assessment and rehabilitation of people with PD, makes recommendations for future research and discusses the use of VR in the clinic. In the assessment of people with PD, VR has been used to manipulate environments to enhance study of the behavioural and neural underpinnings of gait and balance, improving understanding of the motor-cognitive neural circuitry involved. Despite suggestions that VR can provide rehabilitation that is more effective and less labour intensive than non-VR rehabilitation, little evidence exists to date to support these claims. Nevertheless, much unrealised potential exists for the use of VR to provide personalized assessment and rehabilitation that optimises motor learning both in the clinic and home environments, and adapts to change in individuals over time. Design of such systems will require collaboration between all stakeholders to maximise useability, engagement, safety and effectiveness.
\end{abstract}

\section{[H1] INTRODUCTION}

Parkinson disease (PD) is a complex, progressive multi-system neurodegenerative disorder associated with motor and non-motor impairments ${ }^{1}$. The hallmark motor symptoms include bradykinesia, rigidity, tremor and postural instability, 
though with time other complex motor symptoms such as freezing of gait also frequently emerge. PD affects the automaticity of movement and therefore motor deficits are more prominent with distraction, environmental complexity and dual-task load ${ }^{2}$. Gait and balance are affected, influencing everyday mobility even in early disease ${ }^{3}$. Motor learning is impaired in PD, characterized by reduced consolidation and transfer of learning owing to worsening striatal function ${ }^{4}$. To compensate, people with PD use alternative neural circuits, usually involving attention, sensory stimuli and vision ${ }^{5}$. Falling is extremely frequent in $\mathrm{PD}^{6}$ and occurs two or three times more than in the healthy elderly population ${ }^{7}$; this factor, along with cognitive decline and other common non-motor impairments, such as fatigue, apathy, anxiety and depression, produce challenges for engagement in rehabilitation ${ }^{8,9}$. Taken together, optimal training environments for people with PD require consideration of sensory-motor and cognitive input, finely-graded progression levels, optimised adaptation of learning and, critically, safety.

Mounting evidence supports the benefits of rehabilitation, in addition to optimal medical and/or surgical management, for improving gait and balance in people with $\mathrm{PD}^{10-12}$. A variety of evidence-based approaches are used, singly or in combination including individual or group exercise (balance and/or strength and/or aerobic), overground and/or treadmill walking, multi-task training, and/or compensatory movement strategies (that is, directing attention towards key aspects of movement, such as deliberately adopting a wide base of support during a functional task in stance) including cueing (directing attention towards internal cues, such as counting, or external cues, such as floor markers, to regulate stepping behaviour $)^{13}$. However, research to date has focused on overall group-level effects; optimal exercise type, dose and delivery mode for different subgroups of people with PD have not been determined. Therefore, rehabilitation approaches have been limited in their ability to deliver optimal training in a personalized and precise manner across the disease spectrum and the current 'one size fits all' approach is unlikely to provide optimal outcomes ${ }^{13-15}$.

Virtual reality (VR) technology has emerged as a promising tool for researching complex impairments in people with PD and for providing personalized rehabilitation. The goal of using VR in neurorehabilitation is to evoke and/or train brain and behavioural responses, in a controlled laboratory or clinical setting, that are analogous to those that occur in the real world $^{16}$. A key feature of VR is immersivity, that is, the extent to which the user is fully integrated into the virtual environment ${ }^{17}$ (Box 1). Acknowledging that the definition of VR is a source of debate ${ }^{17-20}$, for the purposes of this review 
we define VR broadly as "the application of visual simulations created with computer software that mimic real world or conceivable environments, objects and events in real time, and demand interactivity via ongoing behavioural responses of the user"

The use of VR in people with PD has been largely limited to applications relating to the understanding ${ }^{21}$ and rehabilitation ${ }^{22-26}$ of gait and balance impairments, and this Review focuses on these VR applications compared to the real-world environment. Specifically, we examine the rationale for the use of VR in research and rehabilitation of people with PD, provide a critical appraisal of the current state of the art, make recommendations for future research and outline clinical implications.

\section{[H1] VR FOR EXPLORING UNDERLYING MECHANISMS}

\section{[H2] Rationale}

Our understanding of the precise aetiology underlying gait and balance problems in PD, and in particular freezing of gait (FOG; an episodic symptom defined by a marked reduction or complete absence of forward progression of the feet despite the intention to walk $^{27}$ ) is limited ${ }^{28,29}$. Impaired automaticity forces people with PD to increasingly rely on compensatory neural circuits to control their movements ${ }^{2,30,31}$. Complex gait and balance problems probably arise as the compensatory circuits eventually become affected by progressing nigral and extra-nigral neuropathology ${ }^{32}$. Compensatory motor control then becomes vulnerable to interference from simultaneous task-demands ${ }^{28,29,31}$. These compensatory circuits typically involve fronto-parietal cortices and the cerebellum, although any node that can modulate the motor control networks could be implicated in PD gait and balance dysfunction ${ }^{33-36}$. So far, assessing to what degree complex symptoms, such as FOG, can be attributed to underlying disease, a failure of compensatory circuits, or both, has been difficult. Furthermore, conclusive evidence is lacking as to which nodes in the motor-compensatory circuitry are most involved ${ }^{37}$. FOG and falling frequently co-occur ${ }^{38}$, but are extremely difficult to assess owing to their transient and complex nature. Additionally, people with PD often present with performance bias during testing ${ }^{39}$, limiting translation of research findings to everyday situations. Furthermore, current neuroimaging techniques do not allow for the study of whole-brain activity during ambulation. 
These challenges also apply to clinical assessment of gait and balance. Typically, a range of assessment measures are used, including the following: performance-based measures (such as gait speed and variability with or without additional cognitive and/or manual tasks); balance assessment tools (such as the miniBESTest ${ }^{40}$, which assesses anticipatory and reactive standing balance, dynamic gait, and response to different visual (for example, eyes open versus eyes closed) and somatosensory inputs (such as standing on floor versus standing on foam); and self-assessment questionnaires reporting the person's experience of FOG and fear of falling. These assessments are limited in their ability to simulate 'real-life' conditions and to tease out the contributions of various motor and non-motor impairments to gait and balance performance in each individual presenting with PD.

VR has the potential to address many of the limitations outlined above. First, VR offers an opportunity to study people during the manipulation of sensorimotor contingencies whereby individuals (re-)learn relations between their actions and associated sensory input ${ }^{41}$ that are relevant for gait and balance. For example, in order to improve stepping amplitude symmetry, sensorimotor contingencies can be manipulated in VR so that people with PD step to a target that is visually perceived to be of a smaller range of motion than is actually achieved thereby training their motor systems to produce larger movements during subsequent trials ${ }^{42}$. Moreover, objective behavioural outcomes, physiological measures, as well as mobile neuroimaging can all be collected in a highly controlled and safe laboratory setting while participants feel as if they are ambulating in real-life scenarios ${ }^{16,43}$. Second, VR can simulate situations that would be too dangerous or cumbersome to perform in a clinical setting. For example, having fall-prone people with PD perform gait and balance tasks on raised platforms to elicit anxiety is too dangerous, but immersive VR technology provides the opportunity to induce similar fear responses while participants remain safely on the ground ${ }^{44}$. Third, people with PD have known proprioceptive $^{45}$, vestibular ${ }^{46}$, gaze ${ }^{47}$, cognitive ${ }^{48}$ and perceptual ${ }^{49}$ deficits that influence their gait and balance performance $^{50,51}$. The effect of multisensory-cognitive-motor integration deficits ${ }^{50,52}$ is unclear as disentangling these modalities in real-world experiments is difficult. VR offers the unique capability to manipulate sensory feedback in order to study the effect of multisensory-motor mismatch in PD gait and balance ${ }^{53}$. Taken together, VR provides multiple avenues for gaining insight into pathophysiological processes underlying gait and balance impairments in PD for research purposes as well for clinical assessment, although the use of VR for clinical assessment is still in its infancy. 


\section{[H2] Behavioural results}

\section{[H3] VR fear-of-height paradigm}

VR paradigms that purposefully manipulate sensory information to provoke FOG are revealing valuable insights into FOG triggers, potential pathophysiological processes and possible rehabilitation strategies. A VR-based fear-of-height paradigm was designed to investigate the immediate effect of anxiety on FOG in PD ${ }^{44}$ after prior work based on questionnaire data indicated that these factors could be related ${ }^{54}$. People with PD walked overground while a head mounted display (HMD) visually immersed them in one of two VR environments. In the low-threat condition, the virtual walkway was presented on ground level, while in the high-threat condition the virtual walkway was presented as if it was raised high above the ground ${ }^{44}$ (Table 1). The VR paradigm successfully induced greater levels of anxiety and caused more FOG during the high-threat compared to low-threat condition. Although prior work had shown that subjective anxiety is increased in people with PD and $\mathrm{FOG}^{54}$, this VR fear-of-height paradigm was the first to provide direct evidence that inducing anxiety during gait worsens FOG in PD ${ }^{44}$.

\section{[H3] VR-based treadmill controller}

Similarly, a VR-based treadmill controller interface was developed whereby FOG-provoking scenarios, such as narrow passages, were presented on a large screen while the speed of the treadmill could be adjusted in a feedforward manner based on the acceleration of the legs ${ }^{55}$. This controller interface required people with PD to initiate the first step and allowed for natural stopping of the gait cycle as well as testing for the 'sequence effect' (that is, the rapid sequential reduction in step length that often occurs just before a FOG episode ${ }^{56}$ ) by imposing incremental reductions in step length. All of these potential FOG-triggers are missed when using conventional treadmills. This VR-based treadmill controller elicited FOG in two out of three people with PD while their safety was assured with a harness ${ }^{55}$. Such adaptive treadmillVR interfaces might thus help to overcome the difficulty in eliciting FOG in clinical and research settings and identify person-specific FOG triggers as a basis for personalizing rehabilitation interventions. 


\section{[H3] VR foot-pedal paradigm}

A functional magnetic resonance imaging (fMRI) compatible, semi-immersive VR foot-pedal paradigm was designed to study the behavioural and neural correlates underlying gait impairment in PD, and FOG in particular, while participants were laying supine ${ }^{57}$. Users navigated a $2 \mathrm{D}$ virtual corridor through a first-person perspective by using their feet to alternatively depress a set of foot pedals. Although a true sense of presence could not be achieved, this user-VR interaction did generate a sense of forward progression (Table 1) and required visuomotor and proprioceptive-motor processing that mimicked actual gait. Importantly, the timing interval between alternate foot pedal presses during the VR task was linked to the neural responses obtained with fMRI and real-life gait parameters ${ }^{57,58}$. Finally, the VR environment was designed to present several FOG provoking features, such as environmental triggers (for example, doorways and turns $)^{59,60}$ and cognitive dual-task conditions ${ }^{57}$. In this study, the behavioural measure of FOG was defined as any between-foot-press latency greater than two times the modal foot-press latency, the frequency of which correlated with the severity of clinically observed FOG ${ }^{57}$. Between-foot-press latencies during VR performance were also characterized by an increase in step time variability as seen during actual gait ${ }^{30,61}$. High step-time variability is reflective of reduced gait automaticity and indicates that people with PD who experience FOG are reliant on compensatory attentional circuits to control their stepping ${ }^{30}$.

Two different studies combined the same VR foot pedal paradigm with a Stroop-like response-inhibition task whereby participants were instructed to continue stepping during presentation of congruent colour-word combinations (for example, the word green written in the colour green) and to stop upon presentation of incongruent colour-word combinations (for example, the word green written in the colour blue) ${ }^{60,62}$. These studies revealed that people with PD and FOG responded well to 'simple' congruent cues (such as the word green written in the colour green), but showed considerable delays in their foot press latencies when needing to respond to 'complex' congruent cues (such as the word red written in the colour red) that were implicitly associated with stopping ${ }^{60}$. People with PD and FOG also experienced significant delays when needing to execute stopping in response to incongruent cues, indicating an impaired ability to inhibit ongoing stepping movements ${ }^{62}$. Furthermore, delays were observed in people with PD and FOG when initiating the ‘first step’ forward during VR task performance ${ }^{62}$, indicating an inability to overcome motor inhibition and generate the first stepping response. In agreement with prior findings from neuropsychological testing of executive functioning in PD 
and FOG ${ }^{63-65}$, these findings corroborate the notion that reduced control over the response-inhibition related brain circuits, such as the meso-corticolimbic and cortico-basal ganglia hyper-direct pathways, is implicated in the pathophysiology underlying FOG 60,62 .

\section{[H3] Non-immersive VR via visual augmentation}

Non-immersive VR via visual augmentation has been applied to study gait and balance while people with PD stand on a platform, walk on a treadmill or walk overground. Systems with embedded motion capture are usually confined to research settings ${ }^{43,55,66,67}$; however, other systems can be more easily translated to the clinic. For example, participants with and without FOG were studied while stepping in place on a balance platform in order to navigate through narrow and wide virtual corridors (which often trigger FOG in real life) ${ }^{68}$. Cognitive dual-tasks were superimposed, and statistically significant differences were found between participants with and without FOG in both single-task and dual-task outcomes of stepping time, rhythmicity and symmetry, which is in agreement with previously described gait disturbances in people with PD and FOG ${ }^{69}$. This finding indicates that people with PD and FOG have difficulty dividing attention between motor and cognitive processes or segregating the task components. Another study reported results from an interactive walkway paradigm (Table 1), whereby a standard walkway was augmented with virtual visual patterns to complete complex walking assessments ${ }^{66}$. First, the location and timing of the visual pattern was controlled in real-time on the basis of fullbody kinematics of the individual. Second, virtually presented obstacles reduced risk of tripping and falling during testing. Third, dual-task conditions were presented virtually and made to appear suddenly (for example, changes in gait speed) in order to assess gait adaptability ${ }^{66}$. Assessment using this interactive system was superior to standard clinical tests for distinguishing individuals with and without FOG. This methodology might not only be a useful assessment tool to understand the visual and cognitive compensatory strategies that people with PD and FOG rely on to overcome impairments in motor automaticity while walking in settings approximating real life, but consequent rehabilitation programs could be tailored to these results ${ }^{47,66}$. This idea also holds promise for fully immersive VR in combination with treadmill walking ${ }^{70}$. As treadmills become increasingly versatile and offer split belt facilities (that is, one belt per leg) $)^{71}$ and belt perturbations in multiple directions ${ }^{70}$, it will also be possible to test proprioceptive and vestibular manipulations while walking in virtual environments. 
[H3] VR for assessing balance

In addition to assessing gait, VR also offers opportunities to induce varying levels of visual perturbation during balance tests. Compared to the commonly used eyes-open or eyes-closed conditions, immersive VR applications can decouple the visual and vestibular systems in a more fine-grained manner by providing a wide range of visual perturbations. This feature allows for sensitive measures of balance to be calculated, such as determining the exact thresholds of visual perturbation required to induce falls ${ }^{16,72,73}$. Such systems can be low cost, for example by combining the commercially available Wii balance board (Nintendo) with an immersive VR HMD system, which has been validated against the (more expensive) gold standard Equitest dynamic posturography machine (Neurocom Inc) ${ }^{74}$. Cheap and widely available VRbased balance assessments might prove useful for identifying those people with PD at high risk of falls owing to balance impairment and those who would benefit most from balance training ${ }^{72}$. These systems also allow balance to be assessed in all planes, thereby enabling therapists to better personalize their interventions to the individual's balance deficit ${ }^{74}$. This idea is of particular interest to people with PD who experience FOG, as postural instability, and in particular deficits in medio-lateral weight shifting, have been linked to worse FOG ${ }^{75}$.

\section{[H2] Brain imaging results}

Task-based fMRI still holds the greatest potential to study the neural control of gait and balance, although mobile systems are being validated for assessing cortical activity during actual gait and balance in PD (Supplementary Table 1). To overcome the movement restrictions of fMRI, visual and motor imagery (imagining the movement without actually moving $)^{76}$ or action observation (watching someone else perform the movement) ${ }^{77}$ of gait and balance-related tasks have been used $^{28}$. These techniques activate neurons across similar circuits as during real motor tasks ${ }^{78}$. However, no ongoing behavioural output is generated to ensure that participants are engaged in the task. Furthermore, such techniques preclude assessment of multi-sensory processing ${ }^{50}$ and motor automaticity deficits ${ }^{31}$ that underlie gait difficulty in PD.

FMRI results ${ }^{57}$ from the VR foot pedal paradigm (described earlier) have contributed to our understanding of the neural correlates underlying gait de-automatization and $\mathrm{FOG}^{30,57,79,80}$. In brief, freezing episodes were characterized by motor (that is primary, supplementary motor areas) - cognitive (that is, prefrontal, posterior parietal) circuitry decoupling and decreased activity in the caudate, thalamus, globus pallidus and subthalamic nucleus at the subcortical level ${ }^{57,80}$. In 
addition, presentation of narrow passages in VR induced footstep delays in people with PD and FOG, which were associated with hypo-activation across the pre-supplementary motor area (preSMA) and inversely correlated with the degree of functional connectivity between the preSMA and subthalamic nucleus, two main regions of the hyper-direct cortico-basal ganglia inhibitory pathway ${ }^{81}$. Together, these findings corroborate the idea that FOG is associated with basal ganglia hypoactivation and a resulting overdrive of inhibitory projections to brainstem locomotor centers, and that to compensate, people with PD engage alternative circuits associated with goal-directed and task-related commands to control their gait ${ }^{34,80,81}$. According to these findings, FOG occurs when the communication between these compensatory cognitive and the motor operating circuits fail. Abnormally increased connectivity between limbic regions, in particular the amygdala, and the motor striatum also feed into this mechanism ${ }^{79}$, which might underpin the influence of anxiety in exacerbating $\mathrm{FOG}^{44,79}$.

As mentioned earlier, increased variability in foot press latencies was also found during VR foot pedal task performance, reflecting reduced motor automaticity, which is considered a hallmark feature of PD and FOG ${ }^{30,61}$. Combined fMRI and behavioural results showed for the first time that periods of reduced motor automaticity of stepping movements were associated with increased activity and connectivity across the cognitive control network and orbitofrontal-ventral-striatal limbic circuits in people with PD 'off' their dopaminergic medications; by contrast, during the 'on’ dopamine state, people with PD had lower step time variability and recruited the bilateral cerebellar hemispheres ${ }^{30}$. This VR study thereby provided further evidence of the compensatory cognitive control and cerebellar circuits recruited by people with PD to perform otherwise automatic lower-limb motor tasks ${ }^{30}$.

Despite advances, the VR foot pedal paradigm also has several limitations. The behavioural responses have so far only been derived from foot press latencies. The definition of FOG in this VR paradigm therefore remains arbitrary ${ }^{21,27}$. Still, the degree of FOG tested during the VR task correlated with FOG during actual gait ${ }^{58}$, and a study using electromyography of the legs showed that VR-defined FOG events in eight people with PD were characterized by an increased freezing-ratio ${ }^{82}$ resembling the severe trembling of the legs observed during FOG in the clinic ${ }^{83}$. Future studies adopting electromyography or position data of the feet in large samples are needed to fully validate this paradigm. Furthermore, although alternate foot presses resulted in forward progression, participants were not able to control their 
virtual step length or gaze directions as in actual gait. Although inherently difficult during fMRI with the head fixed, restricted visual exploration of space limits the sense of presence and translation to real life situations. Finally, any task performed in a supine position lacks vestibular and postural influences as well as the whole body coordination required for gait and balance control ${ }^{21}$.

In summary, VR offers unique opportunities to improve our understanding of the behavioural and neural underpinnings of gait and balance impairment in PD. These insights, in turn, will inform development of innovative rehabilitation interventions ${ }^{29}$.

\section{[H1] VR FOR REHABILITATION}

\section{[H2] Rationale}

Current gait and balance rehabilitation interventions for people with PD include overground and/or treadmill walking, balance exercises (including tai chi and dance), strength exercises, multi-task training, cueing and compensatory movement strategies. Evidence from high quality systematic reviews and randomised controlled trials (RCTs) shows that these interventions improve gait and balance ${ }^{10-12,84-87}$. However, substantial variability exists in the response of individual people with PD to rehabilitation ${ }^{9}$, 8 , with, for example, some interventions reducing falls in people with mild disease but increasing falls in people with more severe disease ${ }^{89,90}$. This suggests that the increasing load of motor and non-motor impairments associated with severe disease affects the potential for learning and compensation becomes increasingly compromised. Evidence-based rehabilitation approaches are clearly limited by the extent to which they can be safely tailored to the individual profile of the person with PD, in terms of type, dose and delivery mode, as well as adaptability to immediate and long-term changes in performance. Additionally, rehabilitation interventions tested in RCTs are mostly delivered over a short time period ( $<6$ months), with feedback provided by the therapist in fully-supervised settings, thus facilitating high levels of adherence ${ }^{91}$. However, for optimal outcomes to be achieved in the real-world, rehabilitation would ideally be available throughout the course of the disease, starting at diagnosis when deficits in gait and balance $\mathrm{e}^{92,93}$ and reduced physical activity ${ }^{94}$ are already evident. However, fully-supervised, long-term gait and balance exercise for 
people with PD is neither fundable nor sustainable globally. Novel methods of tailoring rehabilitation and providing feedback in a manner that is challenging and fun, therefore promoting ongoing adherence, are required.

VR rehabilitation has the potential to address these issues to facilitate practice of gait and balance activities. Examples of VR systems used in gait and balance rehabilitation are presented in Table 2. VR rehabilitation applications typically combine real-time motion detection within a virtual environment in the context of a (video)game. The user physically interacts with the virtual environment, viewing an avatar (a character or graphical representation of the user) that mimics the user's movements. Feedback about performance and success is provided both concurrently (during game play) and terminally (at the end of the game). The VR systems most commonly researched in PD rehabilitation to date are nonimmersive.

On the basis of evidence in healthy older adults (aged 60 to 80 years), complex motor-cognitive interaction is known to enhance neuroplasticity and motor learning to a greater degree than simple repetitive motor task learning with no variation $^{95,96}$. The benefits of motor-cognitive interactions are particularly pronounced for the retention and transfer of learning, although initial learning gains might be compromised by increased complexity ${ }^{95}$. In a motor learning disease such as PD, targeting motor-cognitive interactions could be particularly beneficial in early disease stages, enhancing motor performance and generalisation to real life. However, with disease progression motor-cognitive impairments might pose constraints on learning ability ${ }^{97}$. In PD, the learning process relies on altered subcortical and cortical plasticity mechanisms, making learners particularly dependent on external sources of feedback (reviewed elsewhere ${ }^{4}$ ). The many features of PD influence the learning profiles of individuals, and therefore VR-based applications are theoretically better able to address variations in learning profiles than traditional rehabilitation approaches.

A summary of the proposed advantages ${ }^{20,22,24,42,98-114}$ and disadvantages ${ }^{17,22,42,100,102,105,111-115}$ of VR rehabilitation is provided in Box 2, with reference to PD-specific literature where available. Importantly, owing to variations in VR rehabilitation systems, user characteristics, supervision schedules and delivery settings, some features might be an advantage in one context and a disadvantage in another. 


\section{[H2] Evidence}

The many potential advantages of VR rehabilitation outlined above suggest that it is likely to be more effective than other forms of rehabilitation, while providing challenging yet safe and engaging activities. However, little evidence exists to support these claims. Four systematic reviews (Table 3) of high to moderate quality ${ }^{116}$ have investigated VR rehabilitation targeting balance and gait in PD $23,26,99,117$. Meta-analyses of RCTs in these reviews provided moderate certainty of improvement in balance following VR rehabilitation compared to active but non-VR rehabilitation ${ }^{26}$. However, the effect size was small, with the mean difference of 2.7 (95\% CI 1.4 - 4.0) in the Berg Balance Scale unlikely to be clinically important $^{118}$. Additionally, there was low to very low certainty of an improvement in stride length ${ }^{23,26}$, with an effect size that is more likely to be clinically important (mean difference $9.7 \mathrm{~cm}, 95 \%$ CI $4.3-15.0)^{26}$.

Further detail regarding the effectiveness, safety, feasibility and acceptability of VR rehabilitation can be gained by examining individual RCTs targeting gait and balance in people with PD. Supplementary Table 1 summarises 17 such trials ${ }^{119-140}$ of moderate to high quality ${ }^{141}$ (13 of which were included in one or more of the systematic reviews mentioned above, plus an additional 4 RCTs published more recently ${ }^{120,121,136,137}$ ). Nearly all trials delivered gait and balance interventions to people with mild to moderate PD (that is, people who have some postural instability but are physically independent). All but one trial delivered non-immersive VR with visual feedback, with or without additional auditory or haptic feedback, while the remaining trial ${ }^{120}$ did not provide information about the VR system used. The majority of trials used recreational systems ${ }^{119,121-124,126,130-132,135,137}$, two used commercialised rehabilitation-specific systems ${ }^{133,138}$, and four used customised systems ${ }^{126,136,139,140}$. The majority of trials trained standing balance tasks without a change in base of support and/or stepping tasks, except for one trial which trained dance moves ${ }^{123}$, and another which trained treadmill walking $^{126}$. Despite the potential of VR systems to target motor-cognitive tasks, only four trials ${ }^{122,126,131,136}$ explicitly described how this approach was achieved including planning, decision making and response inhibition tasks (for example, specific exercise-based, interactive, videogames with additional motor and/or cognitive task requirements including response inhibition) ${ }^{120,129}$. 
[H3] VR versus non-VR rehabilitation of similar type and dose

A key shortcoming of systematic reviews to date is the confounding influence of exercise type and dose when comparing VR and non-VR rehabilitation. When considering the 11 trials that compared VR and non-VR rehabilitation of a similar type and dose (Table 4, Supplementary Table 2), no consistent evidence exists of VR rehabilitation being more effective in improving gait or balance ${ }^{120-122,124,125,130,131,135,138-140}$. However, the largest and most comprehensive trial to date (the V-time trial) $)^{126-129,142}$ did report some important extra benefits of VR. This trial aimed to reduce fall rates in people at high risk of falls (including a subgroup with PD) using customised VR treadmill training (Table 2) which provided motorcognitive challenges in a simulated, real-life but safe environment, compared to the same dose of treadmill training alone. In the subgroup of people with PD ( $\mathrm{n}=130)$, those people in the VR group had a reduction in fall rates above and beyond the reduction seen in the treadmill group ${ }^{126}$. In two PD subsets, changes in brain activation patterns were observed during actual and imagined complex walking tasks in the VR group, which involved different networks than in the treadmill group $^{127,128}$. This finding supports the authors’ claim that VR rehabilitation promotes neuroplasticity and motor learning, involving a different recruitment of brain regions than motor training alone ${ }^{127,128}$.

\section{[H3] VR rehabilitation versus inactive control interventions}

Further insights can be gained by exploring the four RCTs ${ }^{124,125,136,137,140}$ that included an inactive control group (Table 4, Supplementary Table 2). VR rehabilitation was superior to no intervention ${ }^{124,125,137,140}$ in the three facility-based trials. The remaining trial was the only home-based trial, in which minimally-supervised, customised VR stepping exercise was compared to an inactive control group ${ }^{136}$. Although the VR group perceived improved mobility compared to the inactive group, this difference was not reflected in measured physical outcomes. Further sub-group analysis found a differential effect of intervention according to disease severity with positive effects for the low severity group and potentially negative effects for the higher severity group, suggesting that more severely affected people might require greater supervision and tailoring of exercise to be effective. In addition to the effect of disease severity, the findings of this study might reflect under dosing and/or inadequate supervision in the home environment. 
[H3] Influence of key trial design features on outcomes of VR rehabilitation

Some reports suggest that practicing tasks in immersive VR environments might impair balance and gait performance in the short-term ${ }^{42,111,112}$. However, when considering all 17 trials of non-immersive VR rehabilitation interventions reported in Supplementary Table 2, evidence supports the generalisability of tasks practised in the VR environment to performance of everyday activities in real life $\mathrm{e}^{124,126,137}$. Notably, the aforementioned V-time trial ${ }^{126}$ is an example of a VR intervention that closely replicated the target activity, that is, walking under specifically tailored and progressively challenging motorcognitive conditions. By contrast, the home-based trial mentioned above ${ }^{136}$ was the only study to show a decrement in everyday task performance, that is, the time taken to complete the Timed Up and Go (TUG) test. In this case, the emphasis on accurate, safe stepping in the VR program might have carried over to a slower, but potentially safer, TUG performance and time. In addition, it should be noted that the V-time intervention ${ }^{126}$ was fully-supervised and utilised a safety harness. Indeed, of those trials that reported location and supervision, the majority were performed in a facility with full supervision by a physiotherapist or trainer ${ }^{119,121,125,126,131-133,137,138,140 .}$

VR rehabilitation is thought to effect complex motor-cognitive processes underlying motor learning. Therefore, VR rehabilitation might also improve cognition. However, the focus of reporting to date has been largely on motor outcomes (Supplementary Table 2). Four trials reported cognitive outcomes ${ }^{126,131,136,140}$ showing no effect of VR rehabilitation compared to inactive controls ${ }^{136,140}$ or non-VR rehabilitation ${ }^{126,131,140}$. Similarly, only two trials reported motor-cognitive outcomes (that is, dual-tasking) ${ }^{131,140}$ and found no superiority to comparable non-VR rehabilitation.

Feasibility, safety and acceptability of VR rehabilitation was generally poorly reported (Supplementary Table 2), with four trials providing no feasibility, safety or acceptability data ${ }^{119-140}$. Of the 12 trials that reported adverse events

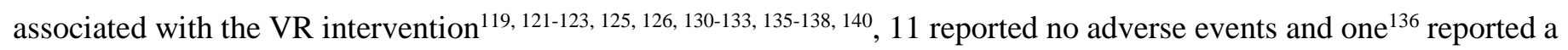
non-injurious fall during unsupervised VR stepping training. Six trials reported adherence to VR-rehabilitation, which ranged from 86 to 100\% (median 98\%) ${ }^{131,133,135-138}$. Although high, adherence to non-VR rehabilitation reported in five trials was also high (range 90 to $100 \%$, median $100^{131,133,135,137,138}$. Given that most trials were fully-supervised, this information might not reflect safety of and adherence to home-based VR interventions. The aforementioned V-time trial was the only trial to explicitly report acceptability ${ }^{129}$. All participants, including those with PD, completed questionnaires 
which showed the VR group were more likely to recommend the intervention to others, reporting greater engagement, challenge and perceived benefits on concentration and obstacle negotiation than the treadmill group. No difference existed between the groups in overall satisfaction.

Despite the proposed lower costs of VR rehabilitation, the only trial that reported on costs ${ }^{122}$ found that the cost of VR delivered via telerehabilitation (€384 per participant) was less than facility-based rehabilitation (€602 per participant). However, this difference was probably due to the VR intervention being delivered in pairs, whereas the facility-based intervention was delivered individually.

\section{[H3] Summary}

In summary, little evidence exists of superiority of VR rehabilitation over non-VR rehabilitation on gait and balance outcomes, although both are superior to no intervention when delivered in a fully-supervised mode. However, most research has used non-immersive, recreational VR systems that might not be optimal as they are not customised to the varied learning difficulties that people with PD experience ${ }^{22,102}$. Additionally, VR rehabilitation has primarily been delivered in fully-supervised, facility-based environments. Therefore, a major limitation of the research to date is that the modest evidence currently supporting VR rehabilitation cannot be generalised to minimally-supervised or unsupervised training conditions in which safety, efficacy and adherence might be compromised. However, a high quality RCT targeting aerobic capacity (rather than balance and gait) in people with PD using non-immersive VR shows promise for incorporation of VR-rehabilitation in the home environment ${ }^{143}$. Both VR-aerobic cycling and non-VR stretching exercise were conducted at home, supported by a motivational app and remote supervision. Both groups showed high adherence

( $>2.5 / 3$ prescribed sessions per week) and few adverse events. Importantly, the VR-aerobic group showed less attenuation of off-state MDS-UPDRS (Movement Disorder Society - Unified Parkinson Disease Rating Scale) motor scores over the 6-month intervention period, suggesting a disease modifying effect with adequately dosed aerobic exercise that is feasible in the home environment. Given the potential benefits of VR rehabilitation and the limitations of current research, there is broad scope for further research and development in this area. 


\section{[H1] FUTURE RESEARCH DIRECTIONS}

\section{[H2] VR in precision medicine}

A new direction in PD research is required, moving from the current 'one size fits all' approach to a 'precision medicine' approach, taking into account the person's clinical presentation, genes, lifestyle and environment ${ }^{144}$. For this purpose, large scale projects are required to identify biomarkers that predict prognosis and response to treatment, such as the Personalized Parkinson Project ${ }^{145}$ and Mobilise- $\mathrm{D}^{146}$. Although precision medicine with respect to medical management of PD is in its infancy ${ }^{144}$, rehabilitation is likely to benefit from this ongoing body of work in the future. In the short term, however, VR has the potential to personalize rehabilitation ${ }^{98}$ in a manner that could complement current practice. Specifically, the ability to manipulate sensorimotor contingencies by simulating tasks that are not possible in the real world and the availability of real-time feedback on performance have the potential to achieve highly personalized assessment and training strategies tailored to both motor and non-motor deficits. For example, VR environments can be used to manipulate situations that provoke FOG and other impairments contributing to fall risk, such as distraction and anxiety. In addition, the potential for VR rehabilitation to provide a more personalized approach by specifically training remediable targets is likely to stimulate the effort, motivation and adherence of the individual beyond that achieved in current practice.

A longitudinal personalized rehabilitation-treatment design for people with long-term upper limb disability after stroke ${ }^{147}$ provides a useful basis for applying such an approach to PD rehabilitation. We propose such a model (Figure 1) illustrating how VR technology could be used to tease out impairments across compensatory circuits that people with PD rely on to maintain gait and balance ${ }^{30,32}$. Subsequently, people with PD are stratified and matched to an appropriate VR type and location, or sequence of types and locations in time. Our model also illustrates that over the course of the disease compensatory network capabilities will change ${ }^{32,36,148}$, requiring adjustments to the therapeutic approach taken. Future studies are needed to test the idea of using VR methodologies for distinguishing between rehabilitation profiles and determine how such phenotypes change over time. 


\section{[H2] Future VR design}

VR is an evolving concept. To date, VR assessment and rehabilitation applications have been developed in parallel with little cross-talk between them. The scope to adapt the most promising immersive VR applications to produce customized dual-purpose applications is enormous. This development requires collaboration between technology experts, therapists and people with PD to ensure that systems provide optimal exercise and motor learning conditions, are reliable and easy to use in the clinic or home environment, and are engaging and acceptable for long-term use.

With respect to facility-based VR rehabilitation systems, synchronized multi-sensory inputs and the inclusion of motorcognitive outcomes need to be incorporated into future designs to facilitate a sense of presence and ecological validity. VR-interventions also need to be developed in the context of a cogent theoretical framework with a clear rationale for the added benefit of VR ${ }^{99}, 149$. For instance, VR training can be designed with the aim to gradually improve gait parameters over time in a personalized manner. Feedback might be offered without distraction first ${ }^{31}$, followed by increasing levels of distraction that might enhance automaticity of walking ${ }^{150}$. Similarly, feedback on performance might be enhanced by external stimuli during initial acquisition of an optimal gait pattern ${ }^{151}$. Subsequently, such input might be faded and then withdrawn to enhance retention ${ }^{152}$. Cognitive dual-tasks could also be added to immersive VR systems to train motorcognitive processing in people with $\mathrm{PD}^{153}$. Such VR systems are ideally suited to in-clinic rehabilitation, when physiotherapists are available to fine tune these parameters on the basis of VR-system outcome measures and observational analysis of the individual's performance.

Ongoing technological advancements might soon allow VR environments to adapt in real-time on the basis of biofeedback obtained from the user's performance. Intra-individual levels of attenuation and inter-individual variability in the effects of VR on physiological measures could be accounted for ${ }^{99}$. For example, the walkway in a VR fear-of-height paradigm might only need to be raised slightly above ground floor to induce a fear response in individuals with trait anxiety, whereas for non-anxious individuals the walkway might need to be raised higher to induce a similar fear response. If attenuation occurs, the VR environment can be modified to maintain challenge (for example, gradually raising the walkway on the basis of physiological measures of anxiety). Similarly, during home-based VR-rehabilitation, progression rules or algorithms ${ }^{154,155}$ could be built into VR applications in which user performance triggers automatic 
adjustment of VR training parameters to the user’s changing performance levels. For example, gait speed and more advanced gait activities are only accessible after users reach a certain level of stability in order to minimize fall risk. These projected innovations will need to be tested in robust RCTs that include comprehensive reporting of the VR intervention protocols (including conceptual framework), VR system used, immersivity of the system, level of motor-cognitive challenge and progression rules. To guide implementation, information about the feasibility, safety and acceptability of VR interventions are required. With respect to acceptability to participants, the use of questionnaires to assess the sense of presence experienced in VR-rehabilitation ${ }^{156}$ is recommended. In addition, taking advantage of technology-based methods will ensure accurate reporting of adherence. With respect to acceptability to health-care providers, cost-effectiveness analyses are crucial to inform implementation decisions.

A major challenge going forward is to keep pace with technological innovations. To prevent redundancy, developers should ensure that VR systems are flexible and adaptable to ongoing technological advances ${ }^{157}$. An overall risk, however, is that VR paradigms over time might become so complex (such as immersive whole-body VR) and costly that they would not meet the need for enhancing practice in supervised and unsupervised environments.

\section{[H1] CLINICAL IMPLICATIONS}

Current evidence indicates that training outcomes are similar for VR versus non-VR based rehabilitation in PD. In addition, all rehabilitation interventions, including VR interventions, have advantages and disadvantages that vary according to the needs and preferences of the people with PD, the type of VR system and specific training protocol used. The skill of the health professional is to analyse these factors and prescribe an intervention accordingly. At this stage the evidence does not support a solely VR-rehabilitation approach. However, identifying people with PD who would gain the greatest benefits from the motivational and engaging aspects of VR to sustain high-dose practice might be useful. Therapists should explore available options with the individual to inform this choice, taking into account motor and nonmotor impairments, fall risk, FOG likelihood and previous experience using computer technology with or without VR. If unsupervised practice is being considered, then a risk analysis needs to be undertaken to ensure that a safety and monitoring plan for unsupervised practice is in place and adequate training to operate the VR system has been provided. 
Therapists should carefully consider the pros and cons when selecting the VR paradigm to achieve optimal training effects. For example, an HMD that presented visual augmented cues during gait did not reduce the severity of FOG compared to traditional cueing strategies ${ }^{67}$. This limited effect was attributed to the HMD being too heavy and uncomfortable to wear, a limited field of view, and insufficient familiarization causing distraction ${ }^{67}$. In addition, some individuals experience motion sickness when using VR, particularly with immersive systems ${ }^{114}$. By contrast, a nonimmersive paradigm in which participants navigated a VR maze under time pressure by stepping on a balance board showed improvement in dual-task performance and reduction in FOG ${ }^{68}$. Furthermore, recreational commercial systems can be too difficult and/or unsafe for some people with $\mathrm{PD}^{22}$, and vary in their effect on cognitive demands, such as decision-making, response inhibition, divided attention and working memory ${ }^{102}$. Although some attempts have been made to assist clinicians to identify appropriate commercial systems and games matched to the individual's impairments ${ }^{102,158}$, criteria are lacking to help guide clinical decision making in PD; and, where available, this information will rapidly become outdated. Therefore, the conceptual framework, promises and pitfalls of technological applications, including VR, need to be incorporated into educational curricula for health professionals involved in rehabilitation.

When selecting VR paradigms, task specificity for obtaining optimal carry-over to everyday activities is an important consideration. During VR implementation, therapists are encouraged to ensure individuals are not using inappropriate movement strategies to meet the goal of the game when exercising, as this has been reported to occur when recreational VR systems are used in rehabilitation of gait and balance after stroke ${ }^{159}$. Adherence to VR might also wane quickly as users get tired of playing the same game. A variety of games with motor-cognitive demands tailored to individual impairments and preferences is likely to enhance motivation and promote adherence.

Given the dopaminergic denervation in PD, any potentially demotivating aspects of VR must be considered, such as negative feedback or having to start over once a mistake is made. Most commercialised VR applications are designed to reach higher scores over time, which are displayed to the user and might negatively impact the user's sense of achievement. This factor might reduce adherence rates and effect motor learning outcomes in people with PD. In the long term, people with PD will need ongoing support to deal with the deterioration in their abilities ${ }^{160}$. Monitoring performance 
in the clinic or remotely will assist therapists to set realistic expectations and collaboratively adjust complexity as the disease progresses. Similarly, subgroups of people with PD, especially in the later stages of the disease, might be impaired in their ability to balance sensory input and cognitive 'top-down' influences over perception ${ }^{161}$. Though speculative at present, this imbalance could lead to unwanted embodied simulations during VR ${ }^{162}$ and affect people's ability to benefit from VR interventions, and might in cases of extreme sensory manipulation lead to adverse outcomes, such as visual hallucinations ${ }^{161}$. Future studies are needed to determine whether people with PD who experience sensory misperceptions or hallucinations are equally able to benefit from immersive VR systems for rehabilitation purposes.

\section{[H1] CONCLUSIONS}

VR has potential to improve our understanding and ability to treat complex impairments in PD by engaging people with PD in enriched and highly individualized complex environments, mimicking real world situations while minimizing risk. However, the full utility of VR for PD rehabilitation has not been achieved yet. To date, little evidence exists of superiority of VR rehabilitation compared to non-VR rehabilitation on gait and balance outcomes, though both are superior to no intervention when delivered in a fully-supervised mode. VR offers opportunities to safely identify an individual's specific FOG triggers and balance deficits, thus informing personalized training targets. To exploit the potential of VR-rehabilitation and to optimise rehabilitation outcomes, researchers are encouraged to design immersive VR applications with integrated assessment and training modules that are tailored to the needs of people with PD and health-care providers. 
1. Kalia LV, Lang AE. Parkinson's disease. Lancet 2015;386:896-912.

2. Wu T, Hallett M. A functional MRI study of automatic movements in patients with Parkinson's disease. Brain 2005;128:2250-2259.

3. Del Din S, Godfrey A, Galna B, Lord S, Rochester L. Free-living gait characteristics in ageing and Parkinson's disease: impact of environment and ambulatory bout length. J Neuroeng Rehabil 2016;13:46.

4. $\quad$ Marinelli L, Trompetto C, Canneva S, et al. Learning "How to Learn": Super Declarative Motor Learning Is Impaired in Parkinson's Disease. Neural Plast 2017;2017:3162087.

5. Stuart S, Lord S, Hill E, Rochester L. Gait in Parkinson's disease: A visuo-cognitive challenge. Neurosci Biobehav Rev 2016;62:76-88.

6. Fasano A, Canning CG, Hausdorff JM, Lord S, Rochester L. Falls in Parkinson's disease: A complex and evolving picture. Mov Disord 2017;32:1524-1536.

7. Pickering RM, Grimbergen YA, Rigney U, et al. A meta-analysis of six prospective studies of falling in Parkinson's disease. Mov Disord 2007;22:1892-1900.

8. Seppi K, Ray Chaudhuri K. Update on treatments for nonmotor symptoms of Parkinson's disease-an evidencebased medicine review. Mov Disord 2019;34:180-198.

9. Strouwen C, Molenaar E, Munks L, et al. Determinants of Dual-Task Training Effect Size in Parkinson Disease: Who Will Benefit Most? J Neurol Phys Ther 2019;43:3-11.

10. Bloem BR, de Vries NM, Ebersbach G. Nonpharmacological treatments for patients with Parkinson's disease. Mov Disord 2015;30:1504-1520.

11. Mak MK, Wong-Yu IS, Shen X, Chung CL. Long-term effects of exercise and physical therapy in people with Parkinson disease. Nat Rev Neurol 2017;13:689-703.

12. Tomlinson CL, Patel S, Meek C, et al. Physiotherapy versus placebo or no intervention in Parkinson's disease. Cochrane Database Syst Rev 2013:CD002817.

13. Nonnekes J, Nieuwboer A. Towards Personalized Rehabilitation for Gait Impairments in Parkinson's Disease. J Parkinsons Dis 2018;8:S101-S106.

14. Ellis T, Rochester L. Mobilizing Parkinson's Disease: The Future of Exercise. J Parkinsons Dis 2018;8:S95-s100.

15. Ellis TD, Dibble LE, Peterson DS. Moving Beyond Effectiveness. J Neurol Phys Ther 2019;43:1-2.

16. Bohil CJ, Alicea B, Biocca FA. Virtual reality in neuroscience research and therapy. Nat Rev Neurosci 2011;12:752-

762.

17. Rose T, Nam CS, Chen KB. Immersion of virtual reality for rehabilitation - Review. Appl Ergon 2018;69:153-161.

18. Weiss P, Kizony R, Feintuch U, Katz N. Virtual reality in neurorehabilitation In: Selzer M, Cohen L, Gage F, Clarke S, Duncan P, eds. Textbook of Neural Repair and Rehabilitation. Cambridge: Cambridge University Press, 2006: 182-197.

19. Perez-Marcos D. Virtual reality experiences, embodiment, videogames and their dimensions in neurorehabilitation. J Neuroeng Rehabil 2018;15:113.

20. Tieri G, Morone G, Paolucci S, losa M. Virtual reality in cognitive and motor rehabilitation: facts, fiction and fallacies. Expert Rev Med Devices 2018;15:107-117.

21. Bluett B, Bayram E, Litvan I. The virtual reality of Parkinson's disease freezing of gait: A systematic review. Parkinsonism Relat Disord 2019;61:26-33.

22. Barry G, Galna B, Rochester L. The role of exergaming in Parkinson's disease rehabilitation: a systematic review of the evidence. J Neuroeng Rehabil 2014;11:33.

23. Dockx K, Bekkers EM, Van den Bergh V, et al. Virtual reality for rehabilitation in Parkinson's disease. Cochrane Database Syst Rev 2016;12:Cd010760.

24. Garcia-Agundez A, Folkerts AK, Konrad R, et al. Recent advances in rehabilitation for Parkinson's Disease with Exergames: A Systematic Review. J Neuroeng Rehabil 2019;16:17.

25. Santos P, Scaldaferri G, Santos L, Ribeiro N, Neto M, Melo A. Effects of the Nintendo Wii training on balance rehabilitation and quality of life of patients with Parkinson's disease: A systematic review and meta-analysis.

NeuroRehabilitation 2019;44:569-577. 
26. Wang B, Shen M, Wang YX, He ZW, Chi SQ, Yang ZH. Effect of virtual reality on balance and gait ability in patients with Parkinson's disease: a systematic review and meta-analysis. Clin Rehabil 2019:269215519843174.

27. Nutt JG, Bloem BR, Giladi N, Hallett M, Horak FB, Nieuwboer A. Freezing of gait: moving forward on a mysterious clinical phenomenon. Lancet Neurol 2011;10:734-744.

28. Fasano A, Herman T, Tessitore A, Strafella AP, Bohnen NI. Neuroimaging of Freezing of Gait. J Parkinsons Dis 2015;5:241-254.

29. Gilat M, Ligia Silva de Lima A, Bloem BR, Shine JM, Nonnekes J, Lewis SJG. Freezing of gait: Promising avenues for future treatment. Parkinsonism Relat Disord 2018;52:7-16.

30. Gilat M, Bell PT, Ehgoetz Martens KA, et al. Dopamine depletion impairs gait automaticity by altering corticostriatal and cerebellar processing in Parkinson's disease. Neuroimage 2017;152:207-220.

31. Hausdorff JM, Balash J, Giladi N. Effects of cognitive challenge on gait variability in patients with Parkinson's disease. J Geriatr Psychiatry Neurol 2003;16:53-58.

32. Bohnen NI, Jahn K. Imaging: What can it tell us about parkinsonian gait? Mov Disord 2013;28:1492-1500.

33. Gilat M, Dijkstra BW, D'Cruz N, Nieuwboer A, Lewis SJG. Functional MRI to Study Gait Impairment in Parkinson's Disease: a Systematic Review and Exploratory ALE Meta-Analysis. Curr Neurol Neurosci Rep 2019;19:49.

34. Lewis SJ, Shine JM. The Next Step: A Common Neural Mechanism for Freezing of Gait. Neuroscientist 2016;22:72-82.

35. Nonnekes J, Ruzicka E, Nieuwboer A, Hallett M, Fasano A, Bloem BR. Compensation Strategies for Gait Impairments in Parkinson Disease: A Review. JAMA Neurol 2019;76:718-725.

36. Peterson DS, Horak FB. Neural Control of Walking in People with Parkinsonism. Physiology (Bethesda) 2016;31:95-107.

37. Bharti K, Suppa A, Tommasin S, et al. Neuroimaging advances in Parkinson's disease with freezing of gait: A systematic review. Neuroimage Clin 2019;24:102059.

38. Bekkers EMJ, Dijkstra BW, Dockx K, Heremans E, Verschueren SMP, Nieuwboer A. Clinical balance scales indicate worse postural control in people with Parkinson's disease who exhibit freezing of gait compared to those who do not: A meta-analysis. Gait Posture 2017;56:134-140.

39. Hillel I, Gazit E, Nieuwboer A, et al. Is every-day walking in older adults more analogous to dual-task walking or to usual walking? Elucidating the gaps between gait performance in the lab and during 24/7 monitoring. Eur Rev Aging Phys Act 2019;16:6.

40. Franchignoni F, Horak F, Godi M, Nardone A, Giordano A. Using psychometric techniques to improve the Balance Evaluation Systems Test: the mini-BESTest. J Rehabil Med 2010;42:323-331.

41. O'Regan JK, Noe A. A sensorimotor account of vision and visual consciousness. Behav Brain Sci 2001;24:939-973; discussion 973-1031.

42. Janeh O, Frundt O, Schonwald B, et al. Gait Training in Virtual Reality: Short-Term Effects of Different Virtual Manipulation Techniques in Parkinson's Disease. Cells 2019;8.

43. Penko AL, Streicher MC, Koop MM, et al. Dual-task Interference Disrupts Parkinson's Gait Across Multiple Cognitive Domains. Neuroscience 2018;379:375-382.

44. Ehgoetz Martens KA, Ellard CG, Almeida QJ. Does anxiety cause freezing of gait in Parkinson's disease? PLoS One 2014;9:e106561.

45. Tan T, Almeida QJ, Rahimi F. Proprioceptive deficits in Parkinson's disease patients with freezing of gait. Neuroscience 2011;192:746-752.

46. $\quad$ Smith PF. Vestibular Functions and Parkinson's Disease. Front Neurol 2018;9:1085.

47. Stuart S, Lord S, Galna B, Rochester L. Saccade frequency response to visual cues during gait in Parkinson's disease: the selective role of attention. Eur J Neurosci 2018;47:769-778.

48. Maidan I, Bernad-Elazari H, Giladi N, Hausdorff JM, Mirelman A. When is Higher Level Cognitive Control Needed for Locomotor Tasks Among Patients with Parkinson's Disease? Brain Topogr 2017;30:531-538.

49. Almeida QJ, Lebold CA. Freezing of gait in Parkinson's disease: a perceptual cause for a motor impairment? J Neurol Neurosurg Psychiatry 2010;81:513-518.

50. Ehgoetz Martens KA, Pieruccini-Faria F, Almeida QJ. Could sensory mechanisms be a core factor that underlies freezing of gait in Parkinson's disease? PLoS One 2013;8:e62602. 
51. Hwang S, Agada P, Grill S, Kiemel T, Jeka JJ. A central processing sensory deficit with Parkinson's disease. Exp Brain Res 2016;234:2369-2379.

52. Pereira MP, Gobbi LT, Almeida QJ. Freezing of gait in Parkinson's disease: Evidence of sensory rather than attentional mechanisms through muscle vibration. Parkinsonism Relat Disord 2016;29:78-82.

53. Ramkhalawansingh R, Butler JS, Campos JL. Visual-vestibular integration during self-motion perception in younger and older adults. Psychol Aging 2018;33:798-813.

54. Lieberman A. Are freezing of gait (FOG) and panic related? J Neurol Sci 2006;248:219-222.

55. Park HS, Yoon JW, Kim J, Iseki K, Hallett M. Development of a VR-based treadmill control interface for gait assessment of patients with Parkinson's disease. IEEE Int Conf Rehabil Robot 2011;2011:5975463.

56. Chee R, Murphy A, Danoudis M, Georgiou-Karistianis N, lansek R. Gait freezing in Parkinson's disease and the stride length sequence effect interaction. Brain 2009;132:2151-2160.

57. Shine JM, Matar E, Ward PB, et al. Exploring the cortical and subcortical functional magnetic resonance imaging changes associated with freezing in Parkinson's disease. Brain 2013;136:1204-1215.

58. Shine JM, Matar E, Bolitho SJ, et al. Modeling freezing of gait in Parkinson's disease with a virtual reality paradigm. Gait Posture 2013;38:104-108.

59. Gilat M, Shine JM, Walton CC, O'Callaghan C, Hall JM, Lewis SJG. Brain activation underlying turning in Parkinson's disease patients with and without freezing of gait: a virtual reality fMRI study. NPJ Parkinsons Dis 2015;1:15020.

60. Matar E, Shine JM, Naismith SL, Lewis SJ. Using virtual reality to explore the role of conflict resolution and environmental salience in freezing of gait in Parkinson's disease. Parkinsonism Relat Disord 2013;19:937-942.

61. Hausdorff JM. Gait dynamics in Parkinson's disease: common and distinct behavior among stride length, gait variability, and fractal-like scaling. Chaos 2009;19:026113.

62. Georgiades MJ, Gilat M, Ehgoetz Martens KA, et al. Investigating motor initiation and inhibition deficits in patients with Parkinson's disease and freezing of gait using a virtual reality paradigm. Neuroscience 2016;337:153-162.

63. Cohen RG, Klein KA, Nomura M, et al. Inhibition, executive function, and freezing of gait. J Parkinsons Dis 2014;4:111-122.

64. Naismith SL, Shine JM, Lewis SJ. The specific contributions of set-shifting to freezing of gait in Parkinson's disease. Mov Disord 2010;25:1000-1004.

65. Vandenbossche J, Deroost N, Soetens E, et al. Conflict and freezing of gait in Parkinson's disease: support for a response control deficit. Neuroscience 2012;206:144-154.

66. Geerse DJ, Roerdink M, Marinus J, van Hilten JJ. Assessing Walking Adaptability in Parkinson's Disease: "The Interactive Walkway". Front Neurol 2018;9:1096.

67. Janssen S, Bolte B, Nonnekes J, et al. Usability of Three-dimensional Augmented Visual Cues Delivered by Smart Glasses on (Freezing of) Gait in Parkinson's Disease. Front Neurol 2017;8:279.

68. Killane I, Fearon C, Newman L, et al. Dual Motor-Cognitive Virtual Reality Training Impacts Dual-Task Performance in Freezing of Gait. IEEE J Biomed Health Inform 2015;19:1855-1861.

69. Hausdorff JM, Schaafsma JD, Balash Y, Bartels AL, Gurevich T, Giladi N. Impaired regulation of stride variability in Parkinson's disease subjects with freezing of gait. Exp Brain Res 2003;149:187-194.

70. Roeles S, Rowe PJ, Bruijn SM, et al. Gait stability in response to platform, belt, and sensory perturbations in young and older adults. Med Biol Eng Comput 2018;56:2325-2335.

71. Seuthe J, D'Cruz N, Ginis P, et al. Split-belt treadmill walking in patients with Parkinson's disease: A systematic review. Gait Posture 2019;69:187-194.

72. Chiarovano E, Wang W, Reynolds P, MacDougall HG. Imbalance: Objective measures versus subjective selfreport in clinical practice. Gait Posture 2018;59:217-221.

73. Chiarovano E, Wang W, Rogers SJ, MacDougall HG, Curthoys IS, de Waele C. Balance in Virtual Reality: Effect of Age and Bilateral Vestibular Loss. Front Neurol 2017;8:5.

74. Chiarovano E, de Waele C, MacDougall HG, Rogers SJ, Burgess AM, Curthoys IS. Maintaining Balance when Looking at a Virtual Reality Three-Dimensional Display of a Field of Moving Dots or at a Virtual Reality Scene. Front Neurol 2015;6:164.

75. Bekkers EMJ, Dijkstra BW, Heremans E, Verschueren SMP, Bloem BR, Nieuwboer A. Balancing between the two: Are freezing of gait and postural instability in Parkinson's disease connected? Neurosci Biobehav Rev 2018;94:113-125. 
76. Peterson DS, Pickett KA, Duncan RP, Perlmutter JS, Earhart GM. Brain activity during complex imagined gait tasks in Parkinson disease. Clin Neurophysiol 2014;125:995-1005.

77. Agosta F, Gatti R, Sarasso E, et al. Brain plasticity in Parkinson's disease with freezing of gait induced by action observation training. J Neurol 2017;264:88-101.

78. Hardwick RM, Caspers S, Eickhoff SB, Swinnen SP. Neural correlates of action: Comparing meta-analyses of imagery, observation, and execution. Neurosci Biobehav Rev 2018;94:31-44.

79. Ehgoetz Martens KA, Hall JM, Georgiades MJ, et al. The functional network signature of heterogeneity in freezing of gait. Brain 2018;141:1145-1160.

80. Shine JM, Matar E, Ward PB, et al. Freezing of gait in Parkinson's disease is associated with functional decoupling between the cognitive control network and the basal ganglia. Brain 2013;136:3671-3681.

81. Matar E, Shine JM, Gilat M, et al. Identifying the neural correlates of doorway freezing in Parkinson's disease. Hum Brain Mapp 2019;40:2055-2064.

82. Georgiades MJ, Shine JM, Gilat M, et al. Hitting the brakes: Pathological subthalamic nucleus activity in Parkinson's disease gait freezing. Brain 2019;142:3906-3916.

83. Schaafsma JD, Balash Y, Gurevich T, Bartels AL, Hausdorff JM, Giladi N. Characterization of freezing of gait subtypes and the response of each to levodopa in Parkinson's disease. Eur J Neurol 2003;10:391-398.

84. Conradsson D, Lofgren N, Nero H, et al. The Effects of Highly Challenging Balance Training in Elderly With Parkinson's Disease: A Randomized Controlled Trial. Neurorehabil Neural Repair 2015;29:827-836.

85. Mehrholz J, Kugler J, Storch A, Pohl M, Hirsch K, Elsner B. Treadmill training for patients with Parkinson's disease. Cochrane Database Syst Rev 2015:CD007830.

86. Shen X, Wong-Yu IS, Mak MK. Effects of Exercise on Falls, Balance, and Gait Ability in Parkinson's Disease: A Meta-analysis. Neurorehabil Neural Repair 2016;30:512-527.

87. Strouwen C, Molenaar E, Munks L, et al. Training dual tasks together or apart in Parkinson's disease: Results from the DUALITY trial. Mov Disord 2017;32:1201-1210.

88. Lofgren N, Conradsson D, Joseph C, Leavy B, Hagstromer M, Franzen E. Factors Associated With Responsiveness to Gait and Balance Training in People With Parkinson Disease. J Neurol Phys Ther 2019;43:42-49.

89. Canning CG, Sherrington C, Lord SR, et al. Exercise for falls prevention in Parkinson disease: a randomized controlled trial. Neurology 2015;84:304-312.

90. Chivers Seymour K, Pickering R, Rochester L, et al. Multicentre, randomised controlled trial of PDSAFE, a physiotherapist-delivered fall prevention programme for people with Parkinson's. J Neurol Neurosurg Psychiatry 2019;90:774-782.

91. Allen NE, Sherrington C, Suriyarachchi GD, Paul SS, Song J, Canning CG. Exercise and motor training in people with Parkinson's disease: a systematic review of participant characteristics, intervention delivery, retention rates, adherence, and adverse events in clinical trials. Parkinsons Dis 2012;2012:854328.

92. Del Din S, Elshehabi M, Galna B, et al. Gait analysis with wearables predicts conversion to parkinson disease. Ann Neurol 2019;86:357-367.

93. Galna B, Lord S, Burn DJ, Rochester L. Progression of gait dysfunction in incident Parkinson's disease: impact of medication and phenotype. Mov Disord 2015;30:359-367.

94. Lord S, Godfrey A, Galna B, Mhiripiri D, Burn D, Rochester L. Ambulatory activity in incident Parkinson's: more than meets the eye? J Neurol 2013;260:2964-2972.

95. Krakauer JW, Hadjiosif AM, Xu J, Wong AL, Haith AM. Motor Learning. Compr Physiol 2019;9:613-663.

96. Pauwels L, Vancleef K, Swinnen SP, Beets IA. Challenge to promote change: both young and older adults benefit from contextual interference. Front Aging Neurosci 2015;7:157.

97. Petzinger GM, Fisher BE, McEwen S, Beeler JA, Walsh JP, Jakowec MW. Exercise-enhanced neuroplasticity targeting motor and cognitive circuitry in Parkinson's disease. Lancet Neurol 2013;12:716-726.

98. Cano Porras D, Sharon H, Inzelberg R, Ziv-Ner Y, Zeilig G, Plotnik M. Advanced virtual reality-based rehabilitation of balance and gait in clinical practice. Ther Adv Chronic Dis 2019;10:2040622319868379.

99. Cano Porras D, Siemonsma P, Inzelberg R, Zeilig G, Plotnik M. Advantages of virtual reality in the rehabilitation of balance and gait: Systematic review. Neurology 2018;90:1017-1025.

100. Celinder D, Peoples H. Stroke patients' experiences with Wii Sports(R) during inpatient rehabilitation. Scand J Occup Ther 2012;19:457-463. 
101. De Keersmaecker E, Lefeber N, Geys M, Jespers E, Kerckhofs E, Swinnen E. Virtual reality during gait training: does it improve gait function in persons with central nervous system movement disorders? A systematic review and meta-analysis. NeuroRehabilitation 2019;44:43-66.

102. dos Santos Mendes FA, Pompeu JE, Modenesi Lobo A, et al. Motor learning, retention and transfer after virtualreality-based training in Parkinson's disease--effect of motor and cognitive demands of games: a longitudinal, controlled clinical study. Physiotherapy 2012;98:217-223.

103. Esculier JF, Vaudrin J, Beriault P, Gagnon K, Tremblay LE. Home-based balance training programme using Wii Fit with balance board for Parkinsons's disease: a pilot study. J Rehabil Med 2012;44:144-150.

104. Hamilton C, Lovarini M, McCluskey A, Folly de Campos T, Hassett L. Experiences of therapists using feedbackbased technology to improve physical function in rehabilitation settings: a qualitative systematic review. Disabil Rehabil 2018:1-12.

105. Hassett L, van den Berg M, Allen N. Feedback-based technologies for adult physical rehabilitation. In: Hayre C, Muller D, Scherer M, eds. Everyday Technologies in Healthcare Florida: CRC Press, 2019: 141-174.

106. Keshner EA. Virtual reality and physical rehabilitation: a new toy or a new research and rehabilitation tool? J Neuroeng Rehabil 2004;1:8.

107. Keshner EA, Fung J. The quest to apply VR technology to rehabilitation: tribulations and treasures. J Vestib Res 2017;27:1-5.

108. Lewis GN, Rosie JA. Virtual reality games for movement rehabilitation in neurological conditions: how do we meet the needs and expectations of the users? Disabil Rehabil 2012;34:1880-1886.

109. Mirelman A, Maidan I, Deutsch JE. Virtual reality and motor imagery: promising tools for assessment and therapy in Parkinson's disease. Mov Disord 2013;28:1597-1608.

110. Mirelman A, Maidan I, Herman T, Deutsch JE, Giladi N, Hausdorff JM. Virtual reality for gait training: can it induce motor learning to enhance complex walking and reduce fall risk in patients with Parkinson's disease? J Gerontol A Biol Sci Med Sci 2011;66:234-240.

111. Parijat P, Lockhart TE, Liu J. Effects of perturbation-based slip training using a virtual reality environment on slipinduced falls. Ann Biomed Eng 2015;43:958-967.

112. Peterson SM, Rios E, Ferris DP. Transient visual perturbations boost short-term balance learning in virtual reality by modulating electrocortical activity. J Neurophysiol 2018;120:1998-2010.

113. Plow M, Finlayson M. A qualitative study exploring the usability of Nintendo Wii Fit among persons with multiple sclerosis. Occup Ther Int 2014;21:21-32.

114. Weech S, Kenny S, Barnett-Cowan M. Presence and Cybersickness in Virtual Reality Are Negatively Related: A Review. Front Psychol 2019;10:158.

115. Wingham J, Adie K, Turner D, Schofield C, Pritchard C. Participant and caregiver experience of the Nintendo Wii Sports after stroke: qualitative study of the trial of Wii in stroke (TWIST). Clin Rehabil 2015;29:295-305.

116. Shea BJ, Reeves BC, Wells G, et al. AMSTAR 2: a critical appraisal tool for systematic reviews that include randomised or non-randomised studies of healthcare interventions, or both. Bmj 2017;358:j4008.

117. Juras G, Brachman A, Michalska J, et al. Standards of Virtual Reality Application in Balance Training Programs in Clinical Practice: A Systematic Review. Games Health J 2019;8:101-111.

118. Godi M, Franchignoni F, Caligari M, Giordano A, Turcato AM, Nardone A. Comparison of reliability, validity, and responsiveness of the mini-BESTest and Berg Balance Scale in patients with balance disorders. Physical therapy 2013;93:158-167.

119. de Melo GEL, Kleiner AFR, Lopes JBP, et al. Effect of virtual reality training on walking distance and physical fitness in individuals with Parkinson's disease. NeuroRehabilitation 2018;42:473-480.

120. Feng H, Li C, Liu J, et al. Virtual Reality Rehabilitation Versus Conventional Physical Therapy for Improving Balance and Gait in Parkinson's Disease Patients: A Randomized Controlled Trial. Med Sci Monit 2019;25:4186-4192.

121. Ferraz DD, Trippo KV, Duarte GP, Neto MG, Bernardes Santos KO, Filho JO. The Effects of Functional Training, Bicycle Exercise, and Exergaming on Walking Capacity of Elderly Patients With Parkinson Disease: A Pilot Randomized Controlled Single-blinded Trial. Arch Phys Med Rehabil 2018;99:826-833.

122. Gandolfi M, Geroin C, Dimitrova E, et al. Virtual Reality Telerehabilitation for Postural Instability in Parkinson's Disease: A Multicenter, Single-Blind, Randomized, Controlled Trial. Biomed Res Int 2017;2017:7962826. 
123. Lee NY, Lee DK, Song HS. Effect of virtual reality dance exercise on the balance, activities of daily living, and depressive disorder status of Parkinson's disease patients. J Phys Ther Sci 2015;27:145-147.

124. Liao Y, Yang Y, Wu Y, Wang R. Virtual Reality-Based Wii Fit Training in Improving Muscle Strength, Sensory Integration Ability, and Walking Abilities in Patients with Parkinson's Disease: A Randomized Controlled Trial. . International Journal of Gerontology 2015;9:190-195.

125. Liao YY, Yang YR, Cheng SJ, Wu YR, Fuh JL, Wang RY. Virtual Reality-Based Training to Improve Obstacle-Crossing Performance and Dynamic Balance in Patients With Parkinson's Disease. Neurorehabil Neural Repair 2015;29:658-667.

126. Mirelman A, Rochester L, Maidan I, et al. Addition of a non-immersive virtual reality component to treadmill training to reduce fall risk in older adults (V-TIME): a randomised controlled trial. Lancet 2016;388:1170-1182.

127. Maidan I, Rosenberg-Katz K, Jacob Y, Giladi N, Hausdorff JM, Mirelman A. Disparate effects of training on brain activation in Parkinson disease. Neurology 2017;89:1804-1810.

128. Maidan I, Nieuwhof F, Bernad-Elazari H, et al. Evidence for Differential Effects of 2 Forms of Exercise on Prefrontal Plasticity During Walking in Parkinson's Disease. Neurorehabil Neural Repair 2018;32:200-208.

129. Dockx K, Alcock L, Bekkers E, et al. Fall-Prone Older People's Attitudes towards the Use of Virtual Reality Technology for Fall Prevention. Gerontology 2017;63:590-598.

130. Pedreira G, Prazeres A, Cruz D, Gomes I, Monteiro L, Melo A. Virtual games and quality of life in Parkinson's disease: a randomised controlled trial. Advances in Parkinson's Disease 2013;2:97-101.

131. Pompeu JE, Mendes FA, Silva KG, et al. Effect of Nintendo Wii-based motor and cognitive training on activities of daily living in patients with Parkinson's disease: a randomised clinical trial. Physiotherapy 2012;98:196-204.

132. Ribas CG, Alves da Silva L, Correa MR, Teive HG, Valderramas S. Effectiveness of exergaming in improving functional balance, fatigue and quality of life in Parkinson's disease: A pilot randomized controlled trial. Parkinsonism Relat Disord 2017;38:13-18.

133. Shen X, Mak MK. Balance and Gait Training With Augmented Feedback Improves Balance Confidence in People With Parkinson's Disease: A Randomized Controlled Trial. Neurorehabil Neural Repair 2014;28:524-535.

134. Shen X, Mak MK. Technology-assisted balance and gait training reduces falls in patients with Parkinson's disease: a randomized controlled trial with 12-month follow-up. Neurorehabil Neural Repair 2015;29:103-111.

135. Shih MC, Wang RY, Cheng SJ, Yang YR. Effects of a balance-based exergaming intervention using the Kinect sensor on posture stability in individuals with Parkinson's disease: a single-blinded randomized controlled trial. J Neuroeng Rehabil 2016;13:78.

136. Song J, Paul SS, Caetano MJD, et al. Home-based step training using videogame technology in people with Parkinson's disease: a single-blinded randomised controlled trial. Clin Rehabil 2018;32:299-311.

137. Tollar J, Nagy F, Hortobagyi T. Vastly Different Exercise Programs Similarly Improve Parkinsonian Symptoms: A Randomized Clinical Trial. Gerontology 2019;65:120-127.

138. van den Heuvel MR, Kwakkel G, Beek PJ, Berendse HW, Daffertshofer A, van Wegen EE. Effects of augmented visual feedback during balance training in Parkinson's disease: a pilot randomized clinical trial. Parkinsonism Relat Disord 2014;20:1352-1358.

139. Yang WC, Wang HK, Wu RM, Lo CS, Lin KH. Home-based virtual reality balance training and conventional balance training in Parkinson's disease: A randomized controlled trial. J Formos Med Assoc 2016;115:734-743.

140. Yen $\mathrm{CY}$, Lin KH, Hu MH, Wu RM, Lu TW, Lin CH. Effects of virtual reality-augmented balance training on sensory organization and attentional demand for postural control in people with Parkinson disease: a randomized controlled trial. Phys Ther 2011;91:862-874.

141. Maher CG, Sherrington C, Herbert RD, Moseley AM, Elkins M. Reliability of the PEDro scale for rating quality of randomized controlled trials. Physical therapy 2003;83:713-721.

142. Mirelman A, Rochester L, Reelick M, et al. V-TIME: a treadmill training program augmented by virtual reality to decrease fall risk in older adults: study design of a randomized controlled trial. BMC Neurol 2013;13:15.

143. van der Kolk NM, de Vries NM, Kessels RPC, et al. Effectiveness of home-based and remotely supervised aerobic exercise in Parkinson's disease: a double-blind, randomised controlled trial. Lancet Neurol 2019.

144. Ryden LE, Lewis SJG. Parkinson's Disease in the Era of Personalised Medicine: One Size Does Not Fit All. Drugs Aging 2019;36:103-113.

145. Bloem BR, Marks WJ, Jr., Silva de Lima AL, et al. The Personalized Parkinson Project: examining disease progression through broad biomarkers in early Parkinson's disease. BMC Neurol 2019;19:160. 
146. Mobilise-D. Available at: www.mobilise-d.eu.

147. Coscia M, Wessel MJ, Chaudary U, et al. Neurotechnology-aided interventions for upper limb motor rehabilitation in severe chronic stroke. Brain 2019;142:2182-2197.

148. Braak H, Del Tredici K, Rub U, de Vos RA, Jansen Steur EN, Braak E. Staging of brain pathology related to sporadic Parkinson's disease. Neurobiol Aging 2003;24:197-211.

149. Wuest S, van de Langenberg R, de Bruin ED. Design considerations for a theory-driven exergame-based rehabilitation program to improve walking of persons with stroke. Eur Rev Aging Phys Act 2014;11:119-129.

150. Yang YR, Cheng SJ, Lee YJ, Liu YC, Wang RY. Cognitive and motor dual task gait training exerted specific training effects on dual task gait performance in individuals with Parkinson's disease: A randomized controlled pilot study. PLoS One 2019;14:e0218180.

151. Nieuwboer A, Kwakkel G, Rochester L, et al. Cueing training in the home improves gait-related mobility in Parkinson's disease: the RESCUE trial. J Neurol Neurosurg Psychiatry 2007;78:134-140.

152. Nieuwboer A, Rochester L, Muncks L, Swinnen SP. Motor learning in Parkinson's disease: limitations and potential for rehabilitation. Parkinsonism Relat Disord 2009;15 Suppl 3:S53-58.

153. Serino S, Baglio F, Rossetto F, et al. Picture Interpretation Test (PIT) 360 degrees : An Innovative Measure of Executive Functions. Sci Rep 2017;7:16000.

154. Delbaere K, Valenzuela T, Woodbury A, et al. Evaluating the effectiveness of a home-based exercise programme delivered through a tablet computer for preventing falls in older community-dwelling people over 2 years: study protocol for the Standing Tall randomised controlled trial. BMJ Open 2015;5:e009173.

155. Ginis P, Nieuwboer A, Dorfman M, et al. Feasibility and effects of home-based smartphone-delivered automated feedback training for gait in people with Parkinson's disease: A pilot randomized controlled trial. Parkinsonism Relat Disord 2016;22:28-34.

156. Sanchez-Vives MV, Slater M. From presence to consciousness through virtual reality. Nat Rev Neurosci 2005;6:332-339.

157. Warland A, Paraskevopoulos I, Tsekleves E, et al. The feasibility, acceptability and preliminary efficacy of a lowcost, virtual-reality based, upper-limb stroke rehabilitation device: a mixed methods study. Disabil Rehabil 2019;41:2119-2134.

158. Pompeu JE, Arduini LA, Botelho AR, et al. Feasibility, safety and outcomes of playing Kinect Adventures! for people with Parkinson's disease: a pilot study. Physiotherapy 2014;100:162-168.

159. Deutsch JE, Brettler A, Smith C, et al. Nintendo wii sports and wii fit game analysis, validation, and application to stroke rehabilitation. Top Stroke Rehabil 2011;18:701-719.

160. O'Brien C, Clemson L, Canning CG. Multiple factors, including non-motor impairments, influence decision making with regard to exercise participation in Parkinson's disease: a qualitative enquiry. Disabil Rehabil 2016;38:472-481.

161. O'Callaghan C, Hall JM, Tomassini A, et al. Visual Hallucinations Are Characterized by Impaired Sensory Evidence Accumulation: Insights From Hierarchical Drift Diffusion Modeling in Parkinson's Disease. Biol Psychiatry Cogn Neurosci Neuroimaging 2017;2:680-688.

162. Riva G, Wiederhold BK, Mantovani F. Neuroscience of Virtual Reality: From Virtual Exposure to Embodied Medicine. Cyberpsychol Behav Soc Netw 2019;22:82-96.

163. Wells GA, Shea B, O'Connell D, et al. Newcastle-Ottawa Scale for non-randomised studies [online]. Available at: http://www.ohri.ca/programs/clinical_epidemiology/oxford.asp.

164. Hoogeboom TJ, Oosting E, Vriezekolk JE, et al. Therapeutic validity and effectiveness of preoperative exercise on functional recovery after joint replacement: a systematic review and meta-analysis. PLoS One 2012;7:e38031.

165. Higgins JP, Altman DG, Gotzsche PC, et al. The Cochrane Collaboration's tool for assessing risk of bias in randomised trials. Bmj 2011;343:d5928.

166. Friston K. The free-energy principle: a unified brain theory? Nat Rev Neurosci 2010;11:127-138. 


\section{Acknowledgements}

M.G. is funded by the European Union's Horizon 2020 research and innovation programme under the Marie SklodowskaCurie grant agreement No 838576”.

\section{Author contributions}

C.G.C., N.E.A., S.S.P. and M.G researched data for the article, made a substantial contribution to discussion of content, wrote and reviewed/edited the manuscript before submission. E.N. and A.N. made a substantial contribution to discussion of content, wrote and reviewed/edited the manuscript before submission. All authors approved the final version of this manuscript.

\section{Competing interests}

The authors declare no competing interests.

\section{Peer review information}

\section{Publisher's note}

Springer Nature remains neutral with regard to jurisdictional claims in published maps and institutional affiliations.

\section{Review criteria}

To identify relevant virtual reality (VR) studies we searched for articles from 1 January 2010 to 1 November 2019. A PubMed search was performed using the terms: "parkinson*” AND "virtual reality” OR "augmented reality” AND "gait” OR "balance” OR “freezing”. The resulting 33 hits and their reference lists were screened for possible insights into the use of VR for exploring the underlying mechanisms of gait and balance impairments in PD. To identify relevant systematic reviews of VR interventions, a PubMed search was performed using the terms: "parkinson*” AND “virtual reality” OR “virtual rehabilitation” OR “augmented reality” OR “exergam*” OR videogam* OR video gam* AND “systematic review”. From the 398 reviews we identified 11 relevant systematic reviews published in English. To identify relevant randomized controlled trials, the reference lists of all relevant systematic reviews were reviewed and relevant randomized controlled trials were extracted. In addition, a PubMed search was performed using the terms: "parkinson*” AND “virtual reality” OR “augmented reality” OR “exergam*” OR videogam* OR video gam* AND “random*”. These two strategies yielded a total of 828 articles including 17 relevant randomized controlled trials published in English. 


\section{KEY POINTS}

1. Virtual reality (VR) might provide unique opportunities to improve understanding of the behavioural and neural underpinnings of gait and balance in people with Parkinson disease.

2. VR environments can be manipulated in ways that are not possible and/or safe in the real-world, with the potential to improve assessment and training of multisensory motor-cognitive integration.

3. Non-immersive VR rehabilitation improves gait and balance when compared to no intervention, but is not superior to non-VR rehabilitation of similar exercise type and dose.

4. Future applications of VR should be tailored to deliver personalized interventions according to each person's profile of deficits and rehabilitation needs.

5. Future developments of VR rehabilitation interventions require collaboration between therapists, technology experts and people with Parkinson disease to ensure optimal, engaging exercise that is acceptable for long-term use.

6. Therapists should consider the conceptual framework, along with the pros and cons, when selecting VR paradigms to optimise training effects with carry-over into everyday activities. 
Table 1. Examples of VR for understanding impairments in PD.

\begin{tabular}{|c|c|c|c|}
\hline Type of VR & Modality & Illustration & Utility \\
\hline Immersive $^{44}$ & $\begin{array}{l}\text { HMD combined } \\
\text { with motion } \\
\text { tracking and/or } \\
\text { other objective } \\
\text { measures of gait } \\
\text { and physiological } \\
\text { status of the user }\end{array}$ & & $\begin{array}{l}\text { Perform experiments that are unsafe or too } \\
\text { cumbersome in real life, such as a fear of heights } \\
\text { paradigm to safely assess impact of anxiety on } \\
\text { gait and balance in PD. } \\
\text { Combine with objective measures of gait and } \\
\text { balance and other physiological measures such } \\
\text { as galvanic skin conductivity and heart rate } \\
\text { variability. } \\
\text { Manipulate multisensory feedback. }\end{array}$ \\
\hline $\begin{array}{l}\text { Semi- } \\
\text { immersive } \\
62\end{array}$ & $\begin{array}{l}\text { Operate foot } \\
\text { pedals to navigate } \\
\text { a virtual corridor }\end{array}$ & & $\begin{array}{l}\text { Combine with neuroimaging techniques (fMRI) } \\
\text { or DBS surgery to investigate the } \\
\text { pathophysiology underlying gait deficits and } \\
\text { FOG in PD. } \\
\text { Ability to present environmental and/or } \\
\text { cognitive triggers known to exacerbate gait } \\
\text { impairment in real life. }\end{array}$ \\
\hline $\begin{array}{l}\text { Non- } \\
\text { immersive }\end{array}$ & $\begin{array}{l}\text { Virtually } \\
\text { projected } \\
\text { walkway }\end{array}$ & & $\begin{array}{l}\text { Combine with mobile neuroimaging } \\
\text { (EEG/fNIRS) to study the pathophysiology } \\
\text { underlying gait and FOG in PD. } \\
\text { Obstacle avoidance with reduced risk of falls } \\
\text { owing to tripping over obstacles. } \\
\text { Ability to manipulate gait conditions without } \\
\text { requiring verbal instructions. } \\
\text { Safety harness can be applied. }\end{array}$ \\
\hline
\end{tabular}

DBS, deep brain stimulation; EEG, electroencephalography; fMRI, functional magnetic resonance imaging; fNIRS,

functional near infrared spectroscopy; FOG, freezing of gait; HMD, head mounted display; PD, Parkinson disease; VR, virtual reality. 
Table 2. Examples of VR systems available for PD rehabilitation ${ }^{\mathrm{a}}$

\begin{tabular}{|c|c|c|c|}
\hline Immersivity & VR Example & Features & Purpose \\
\hline \multicolumn{4}{|c|}{$\begin{array}{l}\text { Category 1. Recreational, commercially available } \\
\text { (Target population: able-bodied people, including children) }\end{array}$} \\
\hline $\begin{array}{l}\text { Non- } \\
\text { immersive }\end{array}$ & $\begin{array}{l}\text { Nintendo Wii } \\
\text { (Nintendo) }\end{array}$ & $\begin{array}{l}\text { Hand-held controllers that } \\
\text { are sensitive to changes in } \\
\text { direction and acceleration. } \\
\text { Might include a balance } \\
\text { board; that is, a force plate, } \\
\text { enabling the user to control } \\
\text { the displacement of their } \\
\text { centre of pressure in real } \\
\text { time. } \\
\text { Displayed on 2D screen. }\end{array}$ & $\begin{array}{l}\text { Not designed specifically for rehabilitation purposes, } \\
\text { but these systems have been researched and are } \\
\text { currently the most commonly used in rehabilitation. }\end{array}$ \\
\hline $\begin{array}{l}\text { Non- } \\
\text { immersive }\end{array}$ & $\begin{array}{l}\text { Xbox Kinect } \\
\text { (Microsoft) }\end{array}$ & $\begin{array}{l}\text { A camera and depth sensors } \\
\text { are used to capture 3D } \\
\text { motion. } \\
\text { Displayed on 2D screen }\end{array}$ & \\
\hline \multicolumn{4}{|c|}{$\begin{array}{l}\text { Category 2. Rehabilitation-specific, commercially available } \\
\text { (Target population: people with disability from neurological and/or other disorders) }\end{array}$} \\
\hline $\begin{array}{l}\text { Non- } \\
\text { immersive to } \\
\text { immersive }\end{array}$ & Caren (Motek) & $\begin{array}{l}\text { VR environment is } \\
\text { integrated with an } \\
\text { instrumented dual-belt } \\
\text { treadmill, 6-degrees of } \\
\text { freedom standing platform } \\
\text { and 3D motion capture } \\
\text { system. Display varies from } \\
\text { 2D flat screen to immersive } \\
\text { dome. Allows manipulation } \\
\text { of visual, somatosensory, } \\
\text { auditory and vestibular } \\
\text { input, for assessment and } \\
\text { training. Safety harness can } \\
\text { be applied }\end{array}$ & $\begin{array}{l}\text { Primarily utilized by researchers and well-resourced } \\
\text { specialized rehabilitation clinics. }\end{array}$ \\
\hline $\begin{array}{l}\text { Non- } \\
\text { Immersive }\end{array}$ & $\begin{array}{l}\text { Humac balance } \\
\text { system (CSMi } \\
\text { for Dynatronics) }\end{array}$ & $\begin{array}{l}\text { Utilises a balance board and } \\
\text { software with games and } \\
\text { activities designed for } \\
\text { people undergoing } \\
\text { rehabilitation. } \\
\text { Displayed on a 2D screen } \\
\text { Safety harness or stable } \\
\text { support (for example, } \\
\text { walking frame) can be } \\
\text { applied. }\end{array}$ & $\begin{array}{l}\text { IMAGE } \\
\text { Aim is to assess and train balance, where balance } \\
\text { training tasks are tailored to level of performance. }\end{array}$ \\
\hline
\end{tabular}




\begin{tabular}{|c|c|c|c|}
\hline \multicolumn{4}{|c|}{$\begin{array}{l}\text { Category 3. Rehabilitation-specific, customized, not commercially available yet } \\
\text { (Target population: people with disability from neurological and/or other disorders) }\end{array}$} \\
\hline Immersive $^{42}$ & $\begin{array}{l}\text { HMD (HTC } \\
\text { VIVE®) with } \\
\text { controllers } \\
\text { attached to legs } \\
\text { and pressure } \\
\text { sensitive gait } \\
\text { mat }\end{array}$ & $\begin{array}{l}\text { Utilises 3-D head mounted } \\
\text { display with controllers } \\
\text { attached to legs to produce } \\
\text { visual-proprioceptive } \\
\text { conflict in VR environment } \\
\text { while walking on a pressure } \\
\text { sensitive mat. } \\
\text { Safety harness can be } \\
\text { applied. }\end{array}$ & $\begin{array}{l}\text { IMAGE } \\
\text { Aim is to improve gait symmetry in people with PD } \\
\text { and FOG. } \\
\text { Visual-proprioceptive conflict condition whereby } \\
\text { virtual foot placement is shifted backwards on the } \\
\text { shorter side to promote taking a longer step. }\end{array}$ \\
\hline $\begin{array}{l}\text { Non- } \\
\text { immersive }{ }^{126}\end{array}$ & $\begin{array}{l}\text { Camera-based } \\
\text { motion capture } \\
\text { (modified } \\
\text { Microsoft } \\
\text { Kinect) plus } \\
\text { virtual } \\
\text { environment }\end{array}$ & $\begin{array}{l}\text { Utilises camera-based } \\
\text { motion capture of feet while } \\
\text { walking. Feet are projected } \\
\text { into the VR environment in } \\
\text { real time on a 2-D screen. } \\
\text { Safety harness is used. }\end{array}$ & $\begin{array}{l}\text { IMAGE } \\
\text { Aim is to reduce falls in people with PD. } \\
\text { VR environment systematically increases the size of } \\
\text { virtual objects to step over and number of } \\
\text { distractions to progress motor-cognitive challenge } \\
\text { while walking. }\end{array}$ \\
\hline
\end{tabular}

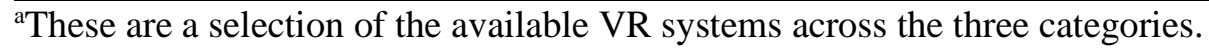

HMD, head mounted display; PD, Parkinson disease; VR, virtual reality. 
Table 3: Systematic Reviews of effects of VR rehabilitation interventions in people with PD

\begin{tabular}{|c|c|c|c|c|}
\hline $\begin{array}{l}\text { Studies and } \\
\text { participants } \\
\text { with PD }\end{array}$ & $\begin{array}{l}\text { Primary study } \\
\text { quality }\end{array}$ & $\begin{array}{l}\text { Primary study } \\
\text { interventions }\end{array}$ & $\begin{array}{l}\text { Key findings on effectiveness, safety } \\
\text { and feasibility }\end{array}$ & $\operatorname{Ref}^{a, b}$ \\
\hline $\begin{array}{l}8 \text { RCTs (370 } \\
\text { participants); } \\
10 \text { non-RCTs } \\
\text { (143 } \\
\text { participants) }\end{array}$ & $\begin{array}{l}\text { Low (overall; } \\
\text { Newcastle Ottawa } \\
\text { Scale }^{163} \text { and } \\
\text { CONTENT } \\
\text { scale }^{164} \text { ). } \\
\text { Moderate (RCTs; } \\
\text { Cochrane risk of } \\
\text { bias tool }^{165} \text { and } \\
\text { CONTENT } \\
\text { scale }^{164} \text { ) }\end{array}$ & $\begin{array}{l}\text { Recreational systems: } 11 \\
\text { studies (10 balance board, } 1 \\
\text { hand-held remote) } \\
\text { Customised systems: } 7 \\
\text { studies ( } 4 \text { balance board, } 1 \\
\text { 3D motion capture, } 2 \text { VR } \\
\text { treadmill training) }\end{array}$ & $\begin{array}{l}\text { Effectiveness compared to active } \\
\text { control: No difference } \\
\text { Safety: } 5 \text { studies report safety but } \\
\text { details not provided } \\
\text { Feasibility: } 12 \text { studies reported } \\
\text { progression, } 6 \text { studies reported } \\
\text { enjoyment/adherence but details not } \\
\text { provided }\end{array}$ & $99^{c}$ \\
\hline $\begin{array}{l}8 \text { RCTs (263 } \\
\text { participants) }\end{array}$ & $\begin{array}{l}\text { Low (Cochrane risk } \\
\text { of bias tool }{ }^{162} \text { ) }\end{array}$ & $\begin{array}{l}\text { Recreational systems: } 6 \text { (4 } \\
\text { balance board, } 2 \text { hand-held } \\
\text { remote) } \\
\text { Customised systems: } 2 \\
\text { trials (both balance board) }\end{array}$ & $\begin{array}{l}\text { Effectiveness compared to active } \\
\text { control: } \uparrow \text { Step and stride length } \\
\text { (Grade: low certainty) } \\
\text { Effectiveness compared to non-active } \\
\text { control: } \uparrow \text { Step and stride length } \\
\text { (Grade: very low certainty); } \uparrow \\
\text { Balance (composite measures) } \\
\text { (Grade: very low certainty); } \downarrow \text { PDQ- } \\
39^{\mathrm{d}} \text { (Grade: very low certainty); } \downarrow \\
\text { UPDRS-2 (ADL) } \\
\text { Safety: No adverse events reported } \\
\text { Feasibility: No difference in drop-out } \\
\text { rates }\end{array}$ & 23 \\
\hline $\begin{array}{l}4 \text { RCTs (60 } \\
\text { participants); } 2 \\
\text { non-RCTs (24 } \\
\text { participants) }\end{array}$ & $\begin{array}{l}\text { Moderate to good } \\
\text { (PEDro score) }\end{array}$ & $\begin{array}{l}\text { Recreational systems: } 3 \\
\text { studies ( } 2 \text { balance board, } 1 \\
\text { 3D motion capture) } \\
\text { Customised systems: } 3 \\
\text { studies (all with balance } \\
\text { boards) }\end{array}$ & $\begin{array}{l}\text { Effectiveness compared to active } \\
\text { control: no difference (mixed results) } \\
\text { Safety: NR } \\
\text { Feasibility: NR }\end{array}$ & $117^{c}$ \\
\hline $\begin{array}{l}12 \text { RCTs (419 } \\
\text { participants) }\end{array}$ & $\begin{array}{l}\text { Moderate to good } \\
\text { (PEDro score) }\end{array}$ & $\begin{array}{l}\text { Recreational systems: } 8 \text { (5 } \\
\text { balance board, } 2 \text { 3D motion } \\
\text { capture, } 1 \text { hand-held } \\
\text { remote) } \\
\text { Customised systems: } 1 \\
\text { dance mat and force plate, } \\
1 \text { force plate and inertial } \\
\text { sensors } \\
\text { Not reported }{ }^{\mathrm{f}}: 2\end{array}$ & $\begin{array}{l}\text { Effectiveness compared to active } \\
\text { control: } \text { 个Berg Balance Scale }{ }^{\mathrm{e}} \text { (Grade: } \\
\text { moderate certainty); } \downarrow \text { Timed Up and } \\
\text { Go }^{\text {de }} \text { (Grade: low certainty); } \uparrow \text { Stride } \\
\text { length (Grade: very low certainty) } \\
\text { Safety: NR } \\
\text { Feasibility: NR }\end{array}$ & 26 \\
\hline
\end{tabular}


aStudies listed alphabetically by first author; ${ }^{b}$ Refs 99, 117 and 26 were moderate quality, and ref 23 was high quality

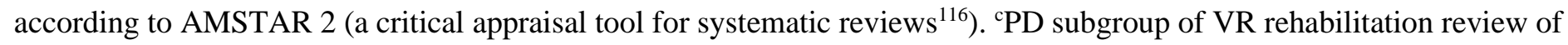
neurological conditions; ${ }^{\mathrm{d}}$ Lower score is better score. ${ }^{\mathrm{e}}$ Meta-analysis showing statistically significant difference improvement in the VR rehabilitation group compared with the control/other intervention group. ${ }^{\mathrm{f}}$ Full text available in Chinese only.

PEDro, Physiotherapy Evidence Database ${ }^{141}$; NR, not reported, RCT, randomized controlled trial; PDQ-39, Parkinson’s Disease Questionnaire - 39 (measures Parkinson’s disease health-related quality of life); UPDRS-2 (ADL): Unified Parkinson’s Disease Rating Scale- 2 (Activities of Daily Living section) 


\begin{tabular}{|c|c|c|c|c|}
\hline $\begin{array}{c}\text { Comparisons (number of } \\
\text { participants) }\end{array}$ & Exercise dose & VR versus non-VR & $\begin{array}{l}\text { VR versus inactive } \\
\text { control }\end{array}$ & $\begin{array}{l}\text { Ref }^{\text {a }} \\
\text { PEDro } \\
\text { score } \\
\text { /10 }\end{array}$ \\
\hline $\begin{array}{l}\text { VR: Training of balance and } \\
\text { walking, VR method not } \\
\text { reported }(\mathrm{n}=14) \\
\text { Non-VR: Traditional } \\
\text { rehabilitation training of } \\
\text { balance and walking }(\mathrm{n}=14)\end{array}$ & $\begin{array}{l}45 \text { min, } 4 \text { times } \\
\text { per week for } 12 \\
\text { weeks }\end{array}$ & $\begin{array}{l}\uparrow \text { Berg Balance Scale } \\
\downarrow \text { Timed up and go }{ }^{\mathrm{b}} \\
\uparrow \text { Functional Gait } \\
\text { Assessment }\end{array}$ & NA & $\begin{array}{l}120 \\
\text { PEDro } 7\end{array}$ \\
\hline $\begin{array}{l}\text { VR: Exergames: balance and } \\
\text { strength }(\mathrm{n}=22) \\
\text { Non-VR: Functional training } \\
\text { (balance and strength exercises) } \\
(\mathrm{n}=25)\end{array}$ & $\begin{array}{l}50 \text { min, } 3 \text { times } \\
\text { per week for } 8 \\
\text { weeks }\end{array}$ & Nil & NA & $\begin{array}{l}121 \\
\text { PEDro } 7\end{array}$ \\
\hline $\begin{array}{l}\text { VR: Balance exergames } \\
\text { delivered via telerehabilitation } \\
(\mathrm{n}=38) \\
\text { Non-VR: Sensory integration } \\
\text { balance training, internal and } \\
\text { external perturbations, dual- } \\
\text { tasks ( } \mathrm{n}=38)\end{array}$ & $\begin{array}{l}50 \text { min, } 3 \text { times } \\
\text { per week for } 7 \\
\text { weeks }\end{array}$ & $\uparrow$ Berg Balance Scale & NA & $\begin{array}{l}122 \\
\text { PEDro } 6\end{array}$ \\
\hline $\begin{array}{l}\text { VR: Exergames: yoga, } \\
\text { strengthening and balance } \\
\text { games + treadmill training } \\
(\mathrm{n}=12) \\
\text { Non-VR: Stretching, } \\
\text { strengthening and balance, and+ } \\
\text { treadmill training ( } \mathrm{n}=12) \\
\text { Control: Fall prevention advice } \\
\text { and continued usual physical } \\
\text { activity }(\mathrm{n}=12)\end{array}$ & $\begin{array}{l}60 \text { min, twice a } \\
\text { week for } 6 \\
\text { weeks }\end{array}$ & $\begin{array}{l}\text { Limits of stability: } \uparrow \\
\text { velocity of COG }\end{array}$ & $\begin{array}{l}\text { Obstacle crossing } \\
\text { while walking: } \uparrow \\
\text { velocity and } \uparrow \text { stride } \\
\text { length } \\
\text { Limits of stability: } \uparrow \\
\text { velocity, } \uparrow \text { excursion } \\
\text { and } \uparrow \text { movement in } \\
\text { intended direction of } \\
\text { COG } \\
\uparrow \text { SOT } \\
\downarrow \text { Timed up and go }{ }^{\mathrm{b}} \\
\uparrow \text { Gait velocity }+ \text { stride } \\
\text { length } \\
\uparrow \text { Functional Gait } \\
\text { Assessment }\end{array}$ & 124,125 \\
\hline
\end{tabular}




\begin{tabular}{|c|c|c|c|c|}
\hline & & & $\begin{array}{l}\uparrow \text { Lower limb muscle } \\
\text { strength } \\
\downarrow \text { PDQ-39 } \\
\downarrow \text { Fear of falling (FES- } \\
\text { I) }\end{array}$ & PEDro 7 \\
\hline $\begin{array}{l}\text { VR: Treadmill walking through } \\
\text { VR environment, negotiating } \\
\text { obstacles, distractors and } \\
\text { multiple routes }(\mathrm{n}=66) \\
\text { Non-VR: Treadmill training } \\
(\mathrm{n}=64)\end{array}$ & $\begin{array}{l}45 \text { min, } 3 \text { times } \\
\text { per week for } 6 \\
\text { weeks }\end{array}$ & $\begin{array}{l}\downarrow \text { Rate of falls } \mathrm{s}^{\mathrm{b}} \\
\downarrow \text { Gait speed variability } \\
\uparrow \text { Foot clearance } \\
\uparrow 2 \text { minute walk distance } \\
\uparrow \text { SPPB: balance, gait } \\
\text { speed }\end{array}$ & NA & $\begin{array}{l}126 \\
\text { PEDro } 8\end{array}$ \\
\hline $\begin{array}{l}\text { VR: Exergames focusing on } \\
\text { strength, balance and aerobics } \\
(\mathrm{n}=22) \\
\text { Non-VR: Physical therapy } \\
\text { focusing on strength, balance } \\
\text { and aerobics }(\mathrm{n}=22)\end{array}$ & $\begin{array}{l}50 \text { min, } 3 \text { times } \\
\text { per week for } 4 \\
\text { weeks }\end{array}$ & Nil & NA & $\begin{array}{l}130 \\
\text { PEDro } 4\end{array}$ \\
\hline $\begin{array}{l}\text { VR: Global exercises and } \\
\text { exergame balance exercises } \\
(n=16) \\
\text { Non-VR: Global exercises and } \\
\text { balance exercises }(n=16)\end{array}$ & $\begin{array}{l}60 \text { min, twice a } \\
\text { week for } 7 \\
\text { weeks }\end{array}$ & Nil & NA & $\begin{array}{l}131 \\
\text { PEDro } 5\end{array}$ \\
\hline $\begin{array}{l}\text { VR: Custom-written balance } \\
\text { exergames }(n=11) \\
\text { Non-VR: Conventional balance } \\
\text { exercises }(n=10)\end{array}$ & $\begin{array}{l}50 \text { min, twice a } \\
\text { week for } 8 \\
\text { weeks }\end{array}$ & $\begin{array}{l}\text { Limit of stability test: } \uparrow \\
\text { movement in intended } \\
\text { direction }\end{array}$ & NA & $\begin{array}{l}135 \\
\text { PEDro } 6\end{array}$ \\
\hline $\begin{array}{l}\text { VR: Exergame: dance stepping } \\
\text { exercise }(n=31) \\
\text { Control: Usual care }(n=29)\end{array}$ & $\begin{array}{l}\geq 15 \min , 3 \\
\text { times per week } \\
\text { for } 12 \text { weeks }\end{array}$ & NA & $\begin{array}{l}\uparrow \text { Timed Up and } \mathrm{Go}^{\mathrm{b}} \text {, } \\
\uparrow \text { self-reported } \\
\text { mobility }\end{array}$ & $\begin{array}{l}136 \\
\text { PEDro } 8\end{array}$ \\
\hline $\begin{array}{l}\text { VR: Exergames: balance and } \\
\text { gait }(n=25) \\
\text { Control: Usual care }(n=24)\end{array}$ & $\begin{array}{l}60 \text { min, } 5 \text { times } \\
\text { per week for } 5 \\
\text { weeks }\end{array}$ & NA & 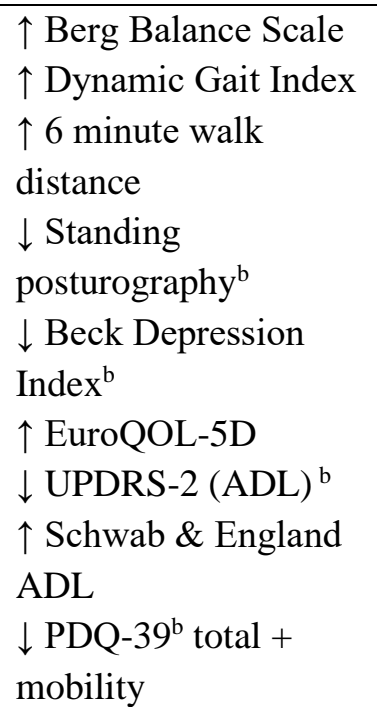 & 137 \\
\hline
\end{tabular}




\begin{tabular}{|c|c|c|c|c|}
\hline & & & & PEDro 6 \\
\hline $\begin{array}{l}\text { VR: Exergame balance training } \\
(\mathrm{n}=17) \\
\text { Non-VR: Conventional balance } \\
\text { training }(\mathrm{n}=16)\end{array}$ & $\begin{array}{l}60 \text { min, twice a } \\
\text { week for } 5 \\
\text { weeks }\end{array}$ & Nil & NA & $\begin{array}{l}138 \\
\text { PEDro } 8\end{array}$ \\
\hline $\begin{array}{l}\text { VR: Exergame balance training } \\
\text { with custom-written exercises } \\
(\mathrm{n}=11) \\
\text { Non-VR: Conventional balance } \\
\text { training }(\mathrm{n}=12)\end{array}$ & $\begin{array}{l}50 \text { min, twice a } \\
\text { week for } 6 \\
\text { weeks }\end{array}$ & Nil & NA & $\begin{array}{l}139 \\
\text { PEDro } 7\end{array}$ \\
\hline $\begin{array}{l}\text { VR: Exergame balance training } \\
\text { with custom-written exercises } \\
(\mathrm{n}=14) \\
\text { Non-VR: Conventional balance } \\
\text { training }(\mathrm{n}=14) \\
\text { Control: Usual care }(\mathrm{n}=14)\end{array}$ & $\begin{array}{l}30 \text { mins, twice a } \\
\text { week for } 6 \\
\text { weeks }\end{array}$ & Nil & $\begin{array}{l}\uparrow \text { SOT-6: with and } \\
\text { without dual task }\end{array}$ & $\begin{array}{l}140 \\
\text { PEDro } 7\end{array}$ \\
\hline
\end{tabular}

${ }^{\text {a} S t u d i e s ~ l i s t e d ~ a l p h a b e t i c a l l y ~ b y ~ f i r s t ~ a u t h o r ; ~}{ }^{b}$ Lower score is better score

ADL, Activities of Daily Living; COG, centre of gravity; EuroQOL-5D, Euro Quality of Life-5D; FES-I, Falls Efficacy

Scale-International; NA, not applicable; PDQ-39: Parkinson’s disease Questionnaire-39; PEDro, Physiotherapy Evidence

Database randomised controlled trial quality score ${ }^{141}$; SOT, Sensory Organisation Test; SPPB, Short Physical

Performance Battery; UPDRS-2 (ADL), Unified Parkinson’s Disease Rating Scale- 2 (Activities of Daily Living section). 
Figure 1. Model of precision rehabilitation using VR to stratify and treat different deficit profiles in PD

A - Top panel presents core motor, proprioceptive, visual and cognitive neural systems that couple with the striatum to facilitate gait and postural control in healthy adults. The bottom panel highlights between-person heterogeneity in the level of deficit in people with PD against the background of increasingly affected striatum and extra-striatal cortical circuits with disease progression (indicated by black colour). Three different profiles of impaired neural activity are shown. Person 1 has early deterioration of cognitive function (indicated by dotted area and becoming black with time). Person 2 starts with deterioration in proprioceptive/sensory integration. Person 3 is characterised by early loss of compensatory visual (attention) function. Notably, with time the spread of degeneration might affect alternative systems in a variable manner, that is, within-person heterogeneity.

B. Potential output of VR-tests in which the various affected systems are loaded and receive a relative deficit score with different projected outcomes for the three different profiles.

C. Precise targeting of deficient compensatory functions during locomotion using VR. Person 1 exposed to Stroop dual tasking to train executive function. Person 2 exposed to walking in the dark towards a narrow doorway to reweight proprioceptive/sensory systems. Person 3 exposed to stepping over obstacles of different heights to train visuo-motor control.

PD, Parkinson disease; VR, virtual reality. 


\section{Box 1 - Immersivity in VR}

VR technology has the capacity to integrate or 'immerse' users into the virtual environment ${ }^{19}$. Bohil et al. suggested that "the level of immersion is determined by the number and range of sensory and motor channels connected to the VR environment and the extent and fidelity of sensory stimulation and responsiveness to motor inputs from the user” ${ }^{\text {}}$. The level of immersion is thought to be important as it imitates the mechanism by which the brain operates, as described by the predictive coding hypothesis ${ }^{162}$. This hypothesis postulates that the brain actively maintains an internal model (simulation) of the body and surrounding space based on sensory and motor experiences. The brain does this in order to make predictions about upcoming sensory input and to select the best actions that minimize the amount of prediction error $^{162,166}$. VR is thought to operate in a similar way by using computer technology to predict the sensory consequences of the user's movements. The unique opportunity to synchronize multiple sensory channels at once thereby allows immersive VR to induce simulations that recreate brain and behavioural responses that a person would also experience in the real world ${ }^{162}$.

Immersivity is thus an essential feature of VR for aiding neurorehabilitation as it allows users to safely engage in simulations of challenging situations from the physical world ${ }^{16}$, such as those that impose a high risk of falls in people with PD. Fully-immersive VR systems use 3D environments, blocking out the perception of the real world, while semiimmersive and non-immersive systems involve varying degrees of perception of both the real world and VR environment. Greater immersivity is considered a key element in achieving embodied simulations and inducing a sense of presence, that is, the psychological product or feeling of the user being physically present in the VR environment. Greater immersivity can be achieved by increasing multimodal stimulus control (for example, changing field of view on the basis of head position is more immersive than watching a static screen), thereby promoting realistic user-environment interactions ${ }^{16,17}$, ${ }^{20}$. In addition, VR environments can be manipulated in a manner that is not possible in the real world (for example, using transient visual perturbations of the VR scene to simulate slipping while walking) ${ }^{111}$, facilitating safety during assessment and training of user responses. 


\section{Box 2. Advantages and disadvantages of VR rehabilitation in $\mathbf{P D}^{\mathrm{a}}$}

\section{[b1] Advantages}

\section{[b2] Clinical}

Promote neuroplasticity and motor learning ${ }^{99,109, \mathrm{~b}}$

Tailored motor-cognitive or limbic challenges directed by visual, auditory or haptic stimuli could lead to improved game performance $^{102}$ and more effective outcomes ${ }^{99,109}$, such as transfer to performance of daily activities ${ }^{24,102,110, b}$ Facilitates standardization and personalized interventions ${ }^{107, c}$

Practice of challenging tasks in a safe environment ${ }^{102,104,109, \mathrm{~b}, \mathrm{c}}$

Potential to safely manipulate sensorimotor conflict as a training strategy with immersive $\mathrm{VR}^{42,111,112, \mathrm{~b}, \mathrm{~d}}$

High-dose practice ${ }^{20,102}$ and adherence, ${ }^{113}$ and quantification of both without relying on self-report ${ }^{20,22,104, b, c}$

Inbuilt task variation and progression in program $98,99,102,109, \mathrm{~b}$

Provision of real-time multisensory feedback ${ }^{98,102,109, \mathrm{~b}}$

[b2] Feasibility

Some VR systems are portable, ${ }^{20,102,113}$ broadly accessible ${ }^{105,113}$ and easy to use $\mathrm{e}^{102,105,113, \mathrm{~b}, \mathrm{c}}$

Some VR systems might lower costs by reducing need for supervision, ${ }^{102}$ thus facilitating home-based rehabilitation ${ }^{103,}$ 106, b,c

Increased motivation, enjoyment and acceptability ${ }^{22,100-102, ~ 104, ~ 108, ~ b, c ~}$

\section{[b1] Disadvantages}

\section{[b2] Clinical}

Physical and cognitive challenges leading to excessive fatigue ${ }^{100, c}$

Increased risk of falls or injury when unsupervised in the home environment ${ }^{22,115, b, c}$

Short-term deterioration in gait with immersive $\mathrm{VR}^{42,111,112, \mathrm{~b}, \mathrm{~d}}$

Eyestrain, dizziness, loss of coordination, motion sickness ${ }^{17,114, \mathrm{c}, \mathrm{d}}$ 
Inaccurate knowledge of performance feedback - correct movement displayed on screen despite use of compensatory movements in the real-world, reinforcing inappropriate movement strategies ${ }^{105, \mathrm{c}}$

Excessive feedback causing uncertainty about where to direct attention ${ }^{105, \mathrm{c}}$

Inability to fade feedback, leading to reliance on feedback ${ }^{105, c}$

Discouraging feedback (for example ‘unbalanced’ in Nintendo Wii-Fit) with large improvements required to progress ${ }^{105}$, $113, \mathrm{c}$

Feedback does not provide specific information about how to improve $\mathrm{e}^{105, \mathrm{c}}$

Difficulty learning to use the VR system ${ }^{113, c}$

[b2] Feasibility

Lack of ability to customise recreational systems to ability level, with some games in recreational systems too hard cognitively, motorically or both ${ }^{102,113,115, b, c}$

Technical difficulties and difficulty manipulating devices ${ }^{105, \mathrm{c}}$

More sophisticated rehabilitation systems are costly and not readily accessible ${ }^{105, \text { c }}$

Difficulty finding physical space for VR system in the home ${ }^{113, c}$

Recreational system visuals can be child-like and therefore less appealing ${ }^{115, c}$

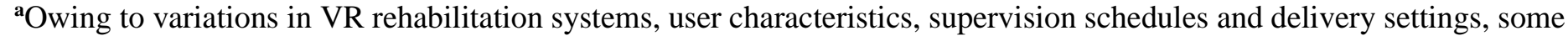
features can be an advantage in one context and a disadvantage in another. ${ }^{b} \mathrm{PD}$ rehabilitation literature. ${ }^{\mathrm{c}}$ Neurological rehabilitation literature. ${ }^{\mathrm{d}}$ Non-neurologically impaired population literature. PD, Parkinson disease; VR, virtual reality. 


\begin{tabular}{|c|c|c|c|}
\hline \multicolumn{4}{|c|}{ A. Understanding impairments } \\
\hline Type of VR & Modality & Illustrations & Utility \\
\hline Immersive 44 & $\begin{array}{l}\text { HMD combined } \\
\text { with motion } \\
\text { tracking and/or } \\
\text { other objective } \\
\text { measures of gait } \\
\text { and physiological } \\
\text { status of the user }\end{array}$ & & $\begin{array}{l}\text {-Perform experiments that are unsafe or } \\
\text { too cumbersome in real life, such as a fear } \\
\text { of heights paradigm to safely assess impact } \\
\text { of anxiety on gait and balance in PD; } \\
\text {-Combine with objective measures of gait } \\
\text { and balance and other physiological } \\
\text { measures, such as galvanic skin } \\
\text { conductivity and heart rate variability; } \\
\text {-Manipulate multisensory-feedback. }\end{array}$ \\
\hline $\begin{array}{l}\text { Semi- } \\
\text { immersive } 59,62\end{array}$ & $\begin{array}{l}\text { Operate foot } \\
\text { pedals to navigate } \\
\text { a virtual corridor }\end{array}$ & & $\begin{array}{l}\text {-Combine with neuroimaging techniques } \\
\text { (fMRI) or DBS surgery to investigate the } \\
\text { pathophysiology underlying gait deficits } \\
\text { and FOG in PD; } \\
\text {-Ability to present environmental and/or } \\
\text { cognitive triggers known to exacerbate gait } \\
\text { impairment in real life. }\end{array}$ \\
\hline $\begin{array}{l}\text { Non- } \\
\text { immersive66 }\end{array}$ & $\begin{array}{l}\text { Virtually } \\
\text { projected } \\
\text { walkway }\end{array}$ & & $\begin{array}{l}\text {-Combine with mobile neuroimaging } \\
\text { (EEG/fNIRS) to study the pathophysiology } \\
\text { underlying gait and FOG in PD; } \\
\text {-Obstacle avoidance with reduced risk for } \\
\text { falls due to tripping over obstacles; } \\
\text {-Ability to manipulate gait conditions } \\
\text { without requiring verbal instructions. } \\
\text {-Safety harness can be applied }\end{array}$ \\
\hline
\end{tabular}




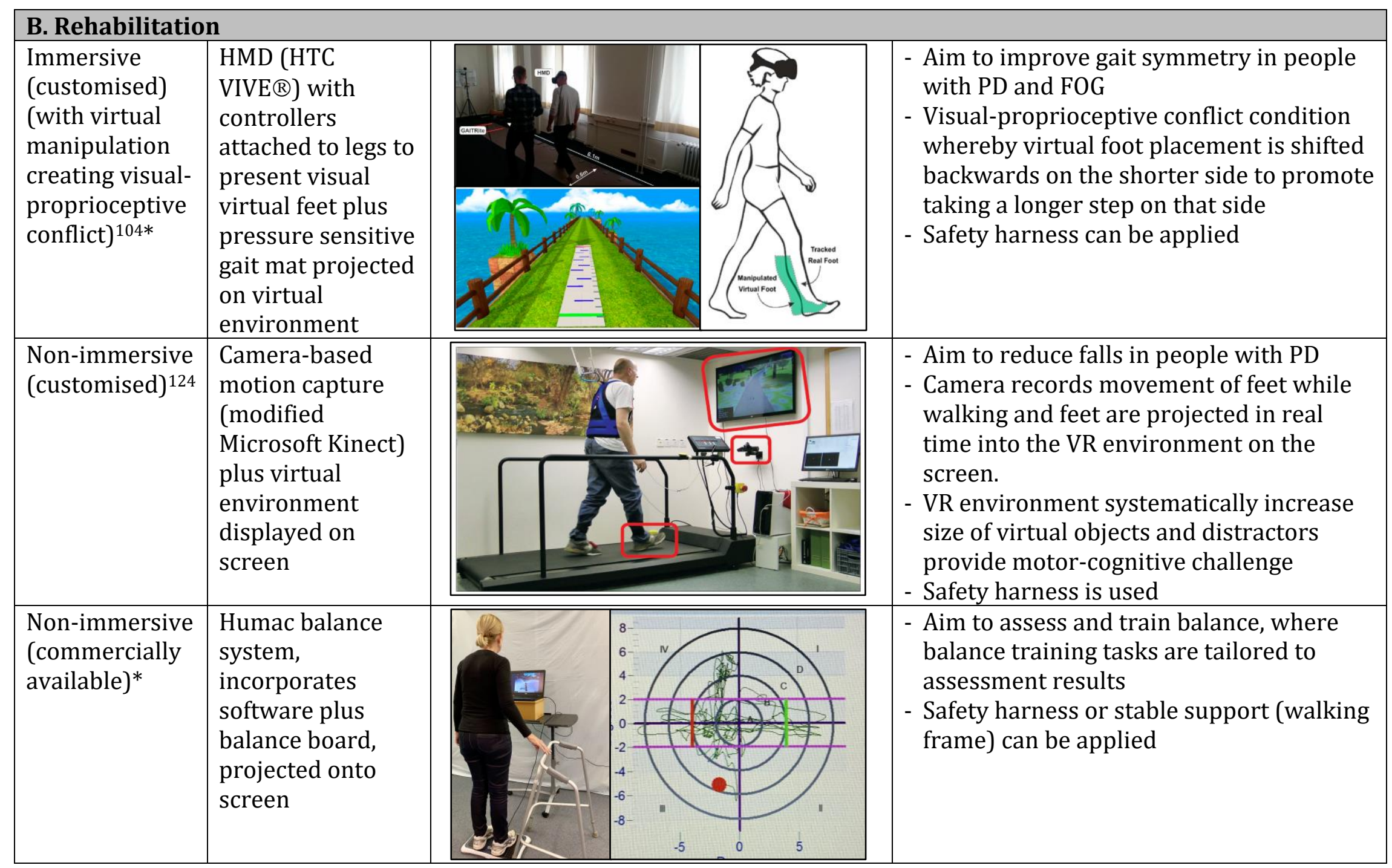





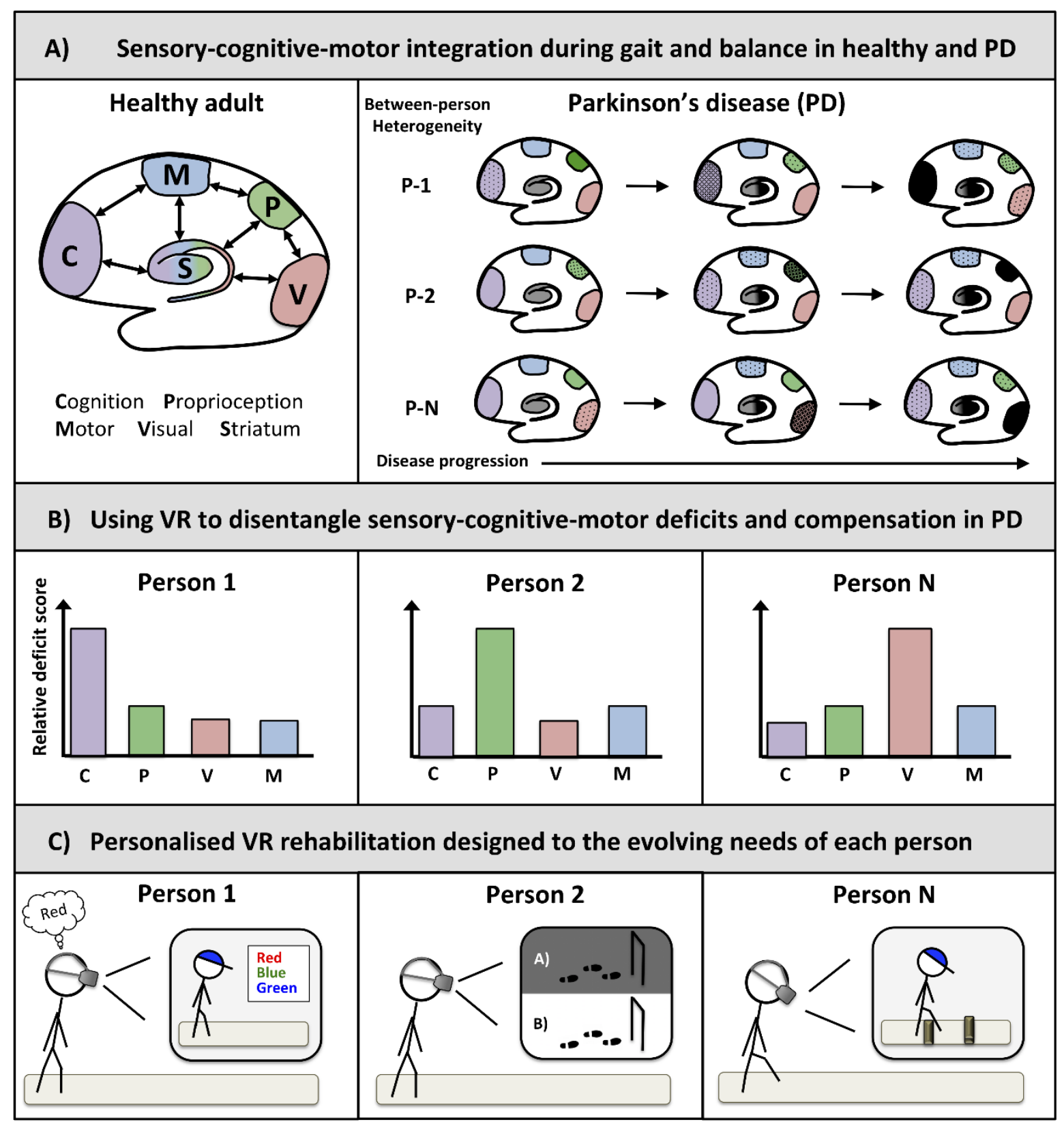


Supplementary Table 1: Pros and cons of neuroimaging techniques for studying PD gait and balance

\begin{tabular}{|c|c|c|c|}
\hline Type & Subtype & Pros & Cons \\
\hline \multicolumn{4}{|c|}{ Cortex only } \\
\hline fNIRS & NA & \multirow{2}{*}{$\begin{array}{l}\text { Mobile (measurement during actual gait and } \\
\text { balance tasks) } \\
\text { Good temporal resolution }\end{array}$} & \multirow{2}{*}{$\begin{array}{l}\text { Does not cover subcortical structures involved in gait and balance } \\
\text { Limited spatial resolution } \\
\text { Sensitive to motion artefact }\end{array}$} \\
\hline EEG & NA & & \\
\hline \multicolumn{4}{|c|}{ Whole brain } \\
\hline $\begin{array}{l}\text { Nuclear } \\
\text { imaging }\end{array}$ & PET \& SPECT & $\begin{array}{l}\text { Whole-brain coverage } \\
\text { Sufficient spatial resolution }\end{array}$ & $\begin{array}{l}\text { Invasive and requires radioactive tracers (nuclear imaging) } \\
\text { Movement restrictions (supine with head fixed and motionless) } \\
\text { Only indirect correlations to gait and balance performance assessed outside the } \\
\text { scanner } \\
\text { Poor temporal resolution }\end{array}$ \\
\hline MRI & $\begin{array}{l}\text { Structural \& Resting } \\
\text { state }\end{array}$ & $\begin{array}{l}\text { Whole-brain coverage } \\
\text { Sufficient (resting MRI) to excellent } \\
\text { (structural MRI) spatial resolution }\end{array}$ & $\begin{array}{l}\text { Movement restrictions (supine with head fixed and motionless) } \\
\text { Only indirect correlations to gait and balance performance assessed outside the } \\
\text { scanner } \\
\text { Poor temporal resolution }\end{array}$ \\
\hline fMRI & Task-based & $\begin{array}{l}\text { Whole-brain coverage } \\
\text { Records BOLD-responses during actual task } \\
\text { performance } \\
\text { Good spatial resolution }\end{array}$ & $\begin{array}{l}\text { Movement restrictions (supine with head fixed and motionless) } \\
\text { Limited temporal resolution } \\
\text { Poor signal to noise ratio }\end{array}$ \\
\hline
\end{tabular}

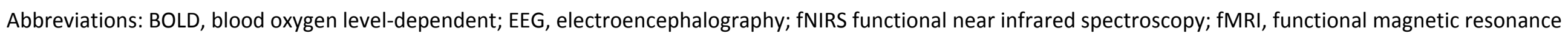
imaging; NA, not applicable; PD, Parkinson disease; PET, Possitron Emission Tomography; SPECT, Single-Photon Emission Computed Tomography. 
Supplementary Table 2: Seventeen randomized controlled trials of VR rehabilitation interventions for gait and balance in people with PD

\begin{tabular}{|c|c|c|c|c|c|c|c|c|c|}
\hline & \multicolumn{2}{|c|}{ Population } & \multirow{2}{*}{$\begin{array}{c}\text { Intervention } \\
\text { VR system } \\
\text { Level of immersion }\end{array}$} & \multirow[b]{2}{*}{ Training } & \multirow[b]{2}{*}{$\begin{array}{l}\text { VR Feedback } \\
\text { VR Progression }\end{array}$} & \multirow[b]{2}{*}{$\begin{array}{l}\quad \text { Dose } \\
\text { minutes } \\
\text { frequency } \\
\text { weeks }\end{array}$} & \multirow[b]{2}{*}{$\begin{array}{l}\quad \text { Delivery } \\
\text { Location } \\
\text { Method } \\
\text { Supervision (\%) }\end{array}$} & \multicolumn{2}{|c|}{ Results } \\
\hline $\begin{array}{l}\text { Author } \\
\text { PEDro Score } \\
\text { Country }\end{array}$ & $\begin{array}{l}\text { Disease } \\
\text { severity }\end{array}$ & $\begin{array}{l}\text { Initial } \\
\text { group sizes } \\
\text { Dropouts + } \\
\text { discontinue } \\
\end{array}$ & & & & & & $\begin{array}{l}\text { Between groups comparisons } \\
\text { (significant differences shown in } \\
\text { bold) }\end{array}$ & $\begin{array}{c}\text { Safety } \\
\text { Feasibility } \\
\text { Acceptability } \\
\text { of the VR intervention }\end{array}$ \\
\hline $\begin{array}{l}\text { De Melo } \\
2018^{119} \# \\
\text { Pedro } 6 \\
\text { Brazil }\end{array}$ & H\&Y 1-3 & $\begin{array}{l}15 \\
2 \\
14 \\
2\end{array}$ & $\begin{array}{l}\text { Kinect Xbox } 360 \\
\text { (Microsoft, Redmond, } \\
\text { WA, USA), on treadmill } \\
\text { Non-immersive }\end{array}$ & $\begin{array}{l}\text { Virtual reality exergame: Your Shape - } \\
\text { Fitness Evolved } 2012 \text { - Run the World } \\
\text { projected onto a screen in front of the } \\
\text { participant. Participant marched on } \\
\text { the spot to simulate walking/running } \\
\text { in the game (VR) } \\
\text { Treadmill (walk or run) (TM) } \\
\text { Conventional gait training (including } \\
\text { obstacle course, steps, walking with } \\
\text { cues) (GT) }\end{array}$ & $\begin{array}{l}\text { Visual - } \\
\text { simulated } \\
\text { walking/running } \\
\text { on the screen } \\
\text { Progression NR }\end{array}$ & $\begin{array}{l}20 \text { minutes } \\
3 / \text { week } \\
4 \text { weeks }\end{array}$ & $\begin{array}{l}\text { Facility } \\
\text { Method NR } \\
100 \% \\
\text { Physiotherapist } \\
\text { supervised }\end{array}$ & $\begin{array}{l}\text { Post-intervention and 1-month } \\
\text { follow-up } \\
\text { Motor } \\
6 \text { minute walk distance* (VR vs } \\
\text { GT, TM vs GT) } \\
\text { Gait speed* (VR vs GT, TM vs } \\
\quad \text { GT) } \\
\text { Gait symmetry } \\
\text { Other } \\
\text { Heart rate before } 6 \text { minute } \\
\text { walk test* (VR vs GT } \text {, TM vs }^{\mathrm{b}} \text {, } \\
\text { GT }^{\mathrm{a}} \text { ) } \\
\text { Heart rate after } 6 \text { minute walk } \\
\text { test } \\
\text { Blood pressure } \\
\text { Oxygen saturation* (TM vs } \\
\text { GT } \\
\text { BORG Rating of Perceived } \\
\text { Exertion* (VR vs GT }^{\mathrm{b}}, \mathrm{TM} \text { vs } \\
\text { GT }^{\mathrm{b}} \text { ) }\end{array}$ & $\begin{array}{l}\text { Safety NR } \\
\text { Feasibility NR } \\
\text { Acceptability NR }\end{array}$ \\
\hline $\begin{array}{l}\text { Feng et al } \\
2019^{120} \\
\text { PEDro } 7 \\
\text { China }\end{array}$ & H\&Y 2.5-4 & $\begin{array}{l}14 \\
0 \\
14 \\
0\end{array}$ & $\begin{array}{l}\text { VR system NR } \\
\text { Level of immersion NR }\end{array}$ & $\begin{array}{l}\text { Virtual reality training of balance and } \\
\text { walking (VR) } \\
\text { Traditional rehabilitation training } \\
\text { according to } 2014 \text { Chinese guide to } \\
\text { treatment of PD (balance exercises in } \\
\text { standing and walking; strength, } \\
\text { walking and rhythm training; visual, } \\
\text { auditory and mirror feedback to train } \\
\text { body posture control; in-bed } \\
\text { translation training) (TE) }\end{array}$ & $\begin{array}{l}\text { Visual feedback } \\
\text { Progression NR }\end{array}$ & $\begin{array}{l}45 \text { minutes } \\
5 / \text { week } \\
12 \text { weeks }\end{array}$ & $\begin{array}{l}\text { Facility } \\
\text { Method NR } \\
100 \% \\
\text { Physiotherapist } \\
\text { supervised }\end{array}$ & $\begin{array}{l}\text { Post intervention } \\
\text { Motor: } \\
\text { Berg Balance Scale } \\
\text { Timed Up and Go } \\
\text { UPDRS-III (motor) } \\
\text { Functional Gait Assessment }\end{array}$ & $\begin{array}{l}\text { Safety NR } \\
\text { Feasibility NR } \\
\text { Acceptability NR }\end{array}$ \\
\hline
\end{tabular}




\begin{tabular}{|c|c|c|c|c|c|c|c|c|c|}
\hline & \multicolumn{2}{|c|}{ Population } & \multirow{2}{*}{$\begin{array}{c}\text { Intervention } \\
\text { VR system } \\
\text { Level of immersion }\end{array}$} & \multirow[b]{2}{*}{ Training } & \multirow[b]{2}{*}{$\begin{array}{l}\text { VR Feedback } \\
\text { VR Progression }\end{array}$} & \multirow[b]{2}{*}{\begin{tabular}{l}
\multicolumn{1}{c}{ Dose } \\
minutes \\
frequency \\
weeks
\end{tabular}} & \multirow[b]{2}{*}{\begin{tabular}{l}
\multicolumn{1}{c}{ Delivery } \\
Location \\
Method \\
Supervision (\%)
\end{tabular}} & \multicolumn{2}{|c|}{ Results } \\
\hline $\begin{array}{l}\text { Author } \\
\text { PEDro Score } \\
\text { Country }\end{array}$ & $\begin{array}{l}\text { Disease } \\
\text { severity }\end{array}$ & $\begin{array}{c}\text { Initial } \\
\text { group sizes } \\
\text { Dropouts + } \\
\text { discontinue } \\
\end{array}$ & & & & & & $\begin{array}{l}\text { Between groups comparisons } \\
\text { (significant differences shown in } \\
\text { bold) }\end{array}$ & $\begin{array}{c}\text { Safety } \\
\text { Feasibility } \\
\text { Acceptability } \\
\text { of the VR intervention }\end{array}$ \\
\hline $\begin{array}{l}\text { Ferraz et al } \\
2018^{121} \\
\text { PEDro } 7 \\
\text { Brazil }\end{array}$ & H\&Y 2-3 & $\begin{array}{l}22 \\
2 \\
25 \\
2 \\
25 \\
5\end{array}$ & $\begin{array}{l}\text { Kinect Xbox } 360 \\
\text { (Microsoft, Redmond, } \\
\text { WA, USA) } \\
\text { Non-immersive }\end{array}$ & $\begin{array}{l}\text { Virtual reality exergames from Kinect } \\
\text { Adventures. (VR) } \\
\text { Functional training (balance and } \\
\text { strength exercises) (F) } \\
\text { Stationary bike (B) }\end{array}$ & $\begin{array}{l}\text { Visual - Full- } \\
\text { body motion via } \\
\text { avatar on } \\
\text { screen } \\
\text { Progression NR }\end{array}$ & $\begin{array}{l}50 \text { minutes } \\
3 / \text { week } \\
8 \text { weeks }\end{array}$ & $\begin{array}{l}\text { Facility } \\
\text { Method NR } \\
100 \% \\
\text { Physiotherapist } \\
\text { supervised }\end{array}$ & $\begin{array}{l}\text { Post intervention } \\
\text { Motor: } \\
6 \text { minute walk test } \\
10 \mathrm{~m} \text { walk } \\
\text { Sit to stand time } \\
\text { Other: } \\
\text { Body Mass Index } \\
\text { Abdominal circumference } \\
\text { PDQ-39 } \\
\text { EuroQol-5D } \\
\text { World Health Organisation } \\
\text { Disability Assessment schedule } \\
2.0 \\
\text { Geriatric Depression Scale }\end{array}$ & $\begin{array}{l}\text { No adverse events } \\
\text { associated with the } \\
\text { intervention } \\
\text { Feasibility NR } \\
\text { Acceptability NR }\end{array}$ \\
\hline $\begin{array}{l}\text { Gandolfi } \\
2017^{122} \# \\
\text { PEDro } 6 \\
\text { Italy }\end{array}$ & H\&Y 2.5-3 & $\begin{array}{l}38 \\
2\end{array}$ & $\begin{array}{l}\text { Nintendo Wii Fit } \\
\text { (Nintendo Inc., Japan) } \\
\text { with balance board } \\
\text { Non-immersive }\end{array}$ & $\begin{array}{l}\text { Virtual reality balance exergames } \\
\text { delivered via telerehabilitation, and a } \\
\text { balance board and screen utilising a } \\
\text { menu of } 10 \text { games focusing on motor } \\
\text { and cognitive training (VR). } \\
\text { Sensory integration balance training: } \\
\text { balance exercises under different } \\
\text { sensory conditions (eyes open, } \\
\text { blindfolded, visual conflict dome, } \\
\text { firm/compliant surfaces, and neck } \\
\text { extensions), internal and external } \\
\text { perturbations, and dual-tasks } \\
\text { progressed over time (SI). }\end{array}$ & $\begin{array}{l}\text { Visual and } \\
\text { auditory } \\
\text { feedback } \\
\text { Progression } \\
\text { based on } \\
\text { motor-cognitive } \\
\text { challenge of } \\
\text { games, clinical } \\
\text { condition and } \\
\text { progress of } \\
\text { participant }\end{array}$ & $\begin{array}{l}50 \text { minutes } \\
3 / \text { week } \\
7 \text { weeks }\end{array}$ & $\begin{array}{l}\text { VR: One session } \\
\text { Facility, then } \\
\text { Home via } \\
\text { videoconference } \\
\text { Individual, (2 } \\
\text { participants } \\
\text { supervised } \\
\text { simultaneously, } \\
\text { + caregiver) } \\
100 \% \\
\text { Physiotherapist } \\
\text { SI: Facility } \\
\text { Individual } \\
\text { 100\% } \\
\text { Physiotherapist } \\
\text { supervised }\end{array}$ & $\begin{array}{l}\text { Post intervention and 1-month } \\
\text { follow-up } \\
\text { Motor } \\
\text { Berg Balance Scale*b } \\
\text { Gait velocity (fast) } \\
\text { Dynamic Gait Index } \\
\text { Rate of falls (previous month) } \\
\text { Other } \\
\text { Activities-Specific Balance } \\
\text { Confidence Scale } \\
\text { PDQ-8 }\end{array}$ & $\begin{array}{l}\text { No adverse events } \\
\text { Satisfaction same in both } \\
\text { groups (satisfaction } \\
\text { questionnaire) } \\
\text { VR telerehabilitation } \\
\text { cost } \\
\text { less(€384/participant) } \\
\text { than } \\
\text { SI (€602/participant) }\end{array}$ \\
\hline $\begin{array}{l}\text { Lee } \\
2015^{123 \wedge \# \sim ~} \\
\text { PEDro } 4 \\
\text { Korea }\end{array}$ & $\begin{array}{l}\text { NR } \\
\text { Independent } \\
\text { ambulation }\end{array}$ & $\begin{array}{l}10 \\
\text { NR }\end{array}$ & $\begin{array}{l}\text { Nintendo Wii (Nintendo } \\
\text { Inc., Japan) } \\
\text { Non-immersive }\end{array}$ & $\begin{array}{l}\text { Virtual reality dance exergame (K-Pop } \\
\text { Dance Festival), mimicking avatar on } \\
\text { screen ( } 30 \text { mins), plus } \\
\text { neurodevelopmental treatment and } \\
\text { functional electrical stimulation ( } 45 \\
\text { min) (VR) } \\
\text { Neurodevelopmental treatment and } \\
\text { functional electrical stimulation (C) }\end{array}$ & $\begin{array}{l}\text { Auditory (heard } \\
\text { word 'perfect') } \\
\text { and haptic } \\
\text { (vibration of } \\
\text { controller) for } \\
\text { successful } \\
\text { performance } \\
\text { Progression NR }\end{array}$ & $\begin{array}{l}\text { VR: } 75 \\
\text { minutes } \\
5 / \text { week } \\
6 \text { weeks } \\
\\
\text { C: } 45 \\
\text { minutes } \\
\text { 5/week } \\
6 \text { weeks }\end{array}$ & NR & $\begin{array}{l}\text { Post intervention } \\
\text { Motor } \\
\text { Berg Balance Scale* } \\
\text { Other } \\
\text { Modified Barthel Index* } \\
\text { Beck Depression Inventory* }\end{array}$ & $\begin{array}{l}\text { Safety NR } \\
\text { Feasibility NR } \\
\text { Acceptability NR }\end{array}$ \\
\hline
\end{tabular}




\begin{tabular}{|c|c|c|c|c|c|c|c|c|c|}
\hline & \multicolumn{2}{|c|}{ Population } & \multirow{2}{*}{$\begin{array}{c}\text { Intervention } \\
\text { VR system } \\
\text { Level of immersion }\end{array}$} & \multirow[b]{2}{*}{ Training } & \multirow[b]{2}{*}{$\begin{array}{l}\text { VR Feedback } \\
\text { VR Progression }\end{array}$} & \multirow[b]{2}{*}{$\begin{array}{l}\quad \text { Dose } \\
\text { minutes } \\
\text { frequency } \\
\text { weeks }\end{array}$} & \multirow[b]{2}{*}{\begin{tabular}{l}
\multicolumn{1}{c}{ Delivery } \\
Location \\
Method ${ }^{\mathrm{V}}$ \\
Supervision (\%) \\
\end{tabular}} & \multicolumn{2}{|l|}{ Results } \\
\hline $\begin{array}{l}\text { Author } \\
\text { PEDro Score } \\
\text { Country }\end{array}$ & $\begin{array}{l}\text { Disease } \\
\text { severity }\end{array}$ & $\begin{array}{l}\text { Initial } \\
\text { group sizes } \\
\text { Dropouts + } \\
\text { discontinue }\end{array}$ & & & & & & $\begin{array}{l}\text { Between groups comparisons } \\
\text { (significant differences shown in } \\
\text { bold) }\end{array}$ & $\begin{array}{c}\text { Safety } \\
\text { Feasibility } \\
\text { Acceptability } \\
\text { of the VR intervention }\end{array}$ \\
\hline $\begin{array}{l}\text { Liao } 2015^{124} \\
\text { Liao } \\
2015^{125} \AA \#^{\sim 8} \\
\text { PEDro } 7 \\
\text { Taiwan }\end{array}$ & H\&Y 1-3 & $\begin{array}{l}12 \\
0\end{array}$ & $\begin{array}{l}\text { Nintendo Wii Fit Plus } \\
\text { (Nintendo Phuten Co, } \\
\text { Ltd, Taiwan) with } \\
\text { balance board } \\
\text { Non-immersive }\end{array}$ & $\begin{array}{l}\text { Virtual reality exercises and } \\
\text { exergames: yoga, strengthening (ankle } \\
\text { weights) and balance games ( } 45 \mathrm{~min})+ \\
\text { treadmill training (15 min) (VR) } \\
\text { Traditional exercise: stretching, } \\
\text { strengthening (ankle weights) and } \\
\text { balance ( } 45 \mathrm{~min})+ \text { treadmill training } \\
\text { (15 min) (TE) } \\
\text { Control: fall prevention advice + } \\
\text { continued usual physical activity (C) }\end{array}$ & $\begin{array}{l}\text { Visual and } \\
\text { auditory } \\
\text { feedback. } \\
\text { Total score } \\
\text { displayed at } \\
\text { end of game } \\
\text { Progression NR }\end{array}$ & $\begin{array}{l}60 \text { minutes } \\
2 / \text { week } \\
6 \text { weeks }\end{array}$ & $\begin{array}{l}\text { Facility } \\
\text { Individual } \\
100 \% \\
\text { Physiotherapist } \\
\text { supervised }\end{array}$ & 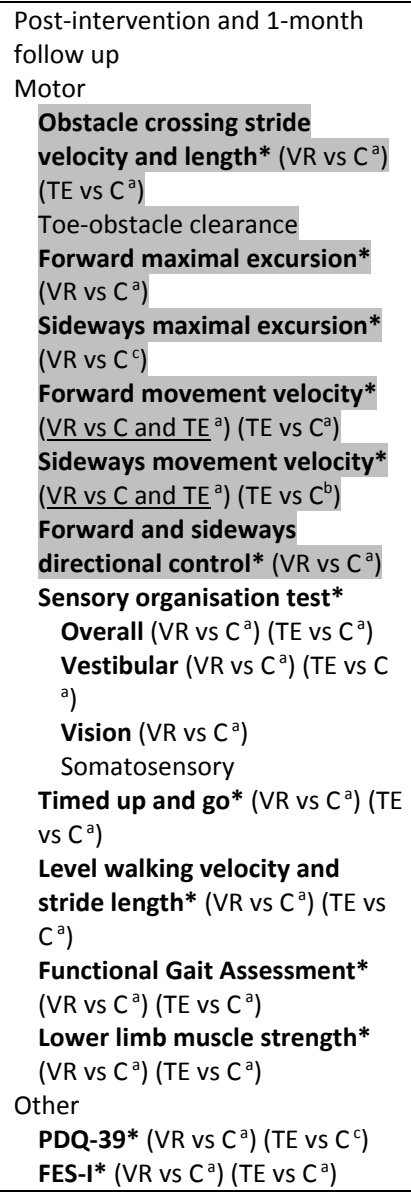 & $\begin{array}{l}\text { Safety harness used for } \\
\text { treadmill training in both } \\
\text { exercise groups } \\
\text { No adverse events } \\
\text { Feasibility NR } \\
\text { Acceptability NR }\end{array}$ \\
\hline
\end{tabular}




\begin{tabular}{|c|c|c|c|c|c|c|c|c|c|}
\hline & \multicolumn{2}{|c|}{ Population } & \multirow{2}{*}{$\begin{array}{c}\text { Intervention } \\
\text { VR system } \\
\text { Level of immersion }\end{array}$} & \multirow[b]{2}{*}{ Training } & \multirow[b]{2}{*}{$\begin{array}{l}\text { VR Feedback } \\
\text { VR Progression }\end{array}$} & \multirow[b]{2}{*}{\begin{tabular}{l}
\multicolumn{1}{c}{ Dose } \\
minutes \\
frequency \\
weeks
\end{tabular}} & \multirow[b]{2}{*}{\begin{tabular}{l}
\multicolumn{1}{c}{ Delivery } \\
Location \\
Method \\
Supervision (\%)
\end{tabular}} & \multicolumn{2}{|c|}{ Results } \\
\hline $\begin{array}{l}\text { Author } \\
\text { PEDro Score } \\
\text { Country }\end{array}$ & $\begin{array}{l}\text { Disease } \\
\text { severity }\end{array}$ & \begin{tabular}{l}
\multicolumn{1}{c}{ Initial } \\
group sizes \\
Dropouts + \\
discontinue
\end{tabular} & & & & & & $\begin{array}{l}\text { Between groups comparisons } \\
\text { (significant differences shown in } \\
\text { bold) }\end{array}$ & $\begin{array}{c}\text { Safety } \\
\text { Feasibility } \\
\text { Acceptability } \\
\text { of the VR intervention }\end{array}$ \\
\hline $\begin{array}{l}\text { Mirelman } \\
2016^{126 \sim} \\
\text { PEDro } 8 \\
\text { Belgium, } \\
\text { Israel, Italy, } \\
\text { Netherlands, } \\
\text { UK }\end{array}$ & $\begin{array}{l}\text { H\&Y 2-3 } \\
\text { PD subset of } \\
\text { larger trial }\end{array}$ & $\begin{array}{l}66 \\
\text { (NR for PD } \\
\text { only) } \\
64 \\
\text { (NR for PD } \\
\text { only) }\end{array}$ & $\begin{array}{l}\text { VR system with motion } \\
\text { capture camera } \\
\text { recording footsteps, } \\
\text { screen with a virtual } \\
\text { environment plus the } \\
\text { footsteps projected } \\
\text { onto it, and a treadmill. } \\
\text { Non-immersive }\end{array}$ & $\begin{array}{l}\text { Virtual reality treadmill training: } \\
\text { walking through a virtual environment } \\
\text { while negotiating challenges such as } \\
\text { obstacles, multiple pathways and } \\
\text { distractors - inducing a cognitive load } \\
\text { demanding attention, planning, dual- } \\
\text { tasking, response selection and } \\
\text { processing of auditory and visual } \\
\text { stimuli. } \\
\text { Treadmill training alone }\end{array}$ & $\begin{array}{l}\text { Visual } \\
\text { and auditory KP } \\
\text { and KR during } \\
\text { training and as } \\
\text { a session } \\
\text { summary } \\
\text { VR Progression: } \\
\text { increasing } \\
\text { motor and } \\
\text { cognitive } \\
\text { challenges } \\
\text { individualized } \\
\text { to participants, } \\
\text { via speed of } \\
\text { treadmill, } \\
\text { duration of } \\
\text { walking bouts } \\
\text { within a } \\
\text { session, size } \\
\text { and frequency } \\
\text { of virtual } \\
\text { obstacles and } \\
\text { distractors. }\end{array}$ & $\begin{array}{l}45 \text { minutes } \\
3 / \text { week } \\
6 \text { weeks }\end{array}$ & $\begin{array}{l}\text { Facility } \\
\text { Individual } \\
100 \% \\
\text { Trainer } \\
\text { supervised }\end{array}$ & $\begin{array}{l}\text { Post intervention and } 6 \text { month } \\
\text { follow up } \\
\text { Motor } \\
\text { Gait speed variability and foot } \\
\text { clearance*a (during obstacle } \\
\text { negotiation) } \\
\text { Gait speed variability (during } \\
\text { usual walking) } \\
\text { Gait speed (during usual walking } \\
\text { and obstacle negotiation) } \\
\mathbf{2} \text { minute walk test*a } \\
\text { SPPB total } \\
\text { SPPB balance*a } \\
\text { SPPB gait speed*a } \\
\text { SPPB sit to stand time } \\
\text { Cognitive } \\
\text { Attention and executive } \\
\text { function } \\
\text { Other } \\
\text { Rate of falls*c } \\
\text { Proportion of repeat fallers } \\
\text { Short form-36 physical } \\
\text { Short form-36 mental }\end{array}$ & $\begin{array}{l}\text { Safety harness used for } \\
\text { treadmill training in both } \\
\text { groups } \\
\text { No adverse events } \\
\text { associated with the } \\
\text { intervention } \\
\text { Feasibility NR } \\
\text { Acceptability NR }\end{array}$ \\
\hline $\begin{array}{l}\text { Maidan } \\
2017^{127} \\
\text { PEDro } 4\end{array}$ & $\begin{array}{l}\text { PD subgroup } \\
\text { (fMRI) }\end{array}$ & $\begin{array}{l}17 \\
17\end{array}$ & As above & & & & & $\begin{array}{l}\text { fMRI improvements* (during } \\
\text { imagined walking with and } \\
\text { without obstacles) }\end{array}$ & \\
\hline $\begin{array}{l}\text { Maidan } \\
2018^{128} \\
\text { PEDro } 4\end{array}$ & $\begin{array}{l}\text { PD subgroup } \\
\text { (fNIRS) }\end{array}$ & $\begin{array}{l}30 \\
34\end{array}$ & As above & & & & & $\begin{array}{l}\text { fNIRS improvements* (during } \\
\text { walking with and without } \\
\text { obstacles and dual-tasks) }\end{array}$ & \\
\hline $\begin{array}{l}\text { Dockx } \\
2017^{129} \\
\text { PEDro } 5\end{array}$ & Full sample & $\begin{array}{l}144 \\
137\end{array}$ & As above & & & & & $\begin{array}{l}\text { Attitudes towards fall } \\
\text { prevention exercise*a } \\
\text { User satisfaction questionnaire }\end{array}$ & \\
\hline $\begin{array}{l}\text { Pedreira } \\
2013^{130 \wedge} \\
\text { Brazil } \\
\text { PEDro } 4\end{array}$ & H\&Y 1-3 & $\begin{array}{l}22 \\
6 \\
22 \\
6\end{array}$ & $\begin{array}{l}\text { Nintendo Wii (Nintendo } \\
\text { Inc., Japan) } \\
\text { Non-immersive }\end{array}$ & $\begin{array}{l}\text { Virtual reality exergames focusing on } \\
\text { strength, balance and aerobics } \\
\text { Physical therapy: trunk and limb } \\
\text { mobilisation, balance, muscle } \\
\text { strengthening, rhythmic movement, } \\
\text { postural alignment, dual task practice, } \\
\text { bimanual tasks, and cardiorespiratory } \\
\text { and gait training. }\end{array}$ & $\begin{array}{l}\text { Visual and } \\
\text { auditory } \\
\text { feedback } \\
\text { Progression NR }\end{array}$ & $\begin{array}{l}50 \text { minutes } \\
3 / \text { week } \\
4 \text { weeks }\end{array}$ & NR & $\begin{array}{l}\text { Post intervention } \\
\text { Other } \\
\text { PDQ-39 total } \\
\text { PDQ-39 mobility } \\
\text { PDQ-39 ADL } \\
\text { PDQ-39 Emotional well being } \\
\text { PDQ-39 Stigma } \\
\text { PDQ-39 Social support } \\
\text { PDQ-39 Cognition } \\
\text { PDQ-39 Communication } \\
\text { PDQ-39 Bodily discomfort }\end{array}$ & $\begin{array}{l}\text { Safety NR } \\
\text { Feasibility NR } \\
\text { Acceptability NR }\end{array}$ \\
\hline
\end{tabular}




\begin{tabular}{|c|c|c|c|c|c|c|c|c|c|}
\hline & \multicolumn{2}{|c|}{ Population } & \multirow{2}{*}{$\begin{array}{c}\text { Intervention } \\
\text { VR system } \\
\text { Level of immersion }\end{array}$} & \multirow[b]{2}{*}{ Training } & \multirow[b]{2}{*}{$\begin{array}{l}\text { VR Feedback } \\
\text { VR Progression }\end{array}$} & \multirow[b]{2}{*}{\begin{tabular}{l}
\multicolumn{1}{c}{ Dose } \\
minutes \\
frequency \\
weeks
\end{tabular}} & \multirow[b]{2}{*}{\begin{tabular}{l}
\multicolumn{1}{c}{ Delivery } \\
Location \\
Method \\
Supervision (\%)
\end{tabular}} & \multicolumn{2}{|c|}{ Results } \\
\hline $\begin{array}{l}\text { Author } \\
\text { PEDro Score } \\
\text { Country }\end{array}$ & $\begin{array}{l}\text { Disease } \\
\text { severity }\end{array}$ & \begin{tabular}{l}
\multicolumn{1}{c}{ Initial } \\
group sizes \\
Dropouts + \\
discontinue
\end{tabular} & & & & & & $\begin{array}{l}\text { Between groups comparisons } \\
\text { (significant differences shown in } \\
\text { bold) }\end{array}$ & $\begin{array}{c}\text { Safety } \\
\text { Feasibility } \\
\text { Acceptability } \\
\text { of the VR intervention }\end{array}$ \\
\hline $\begin{array}{l}\text { Pompeu } \\
2012^{131 \wedge \#} \\
\text { Pedro } 5 \\
\text { Brazil }\end{array}$ & H\&Y 1-2 & $\begin{array}{l}16 \\
0 \\
16 \\
0\end{array}$ & $\begin{array}{l}\text { Nintendo Wii Fit } \\
\text { (Nintendo Inc., Japan) } \\
\text { with balance board } \\
\text { Non-immersive }\end{array}$ & $\begin{array}{l}\text { Global exercises ( } 30 \mathrm{~min})+ \text { virtual } \\
\text { reality exergame balance exercises, } 10 \\
\text { games focusing on motor and } \\
\text { cognitive training ( } 30 \text { mins) } \\
\text { Global exercises ( } 30 \mathrm{~min})+ \text { balance } \\
\text { exercises ( } 30 \mathrm{~min}): \text { similar to Wii Fit } \\
\text { exercises without the provision of } \\
\text { external cues, feedback and cognitive } \\
\text { stimulation }\end{array}$ & $\begin{array}{l}\text { Visual and } \\
\text { auditory } \\
\text { feedback } \\
\text { Progression NR }\end{array}$ & $\begin{array}{l}60 \text { minutes } \\
2 / \text { week } \\
7 \text { weeks }\end{array}$ & $\begin{array}{l}\text { Facility } \\
\text { Individual } \\
100 \% \\
\text { Physiotherapist } \\
\text { supervised }\end{array}$ & $\begin{array}{l}\text { Post-intervention and } 2 \text { month } \\
\text { follow up } \\
\text { Motor } \\
\text { Berg balance scale } \\
\text { Single leg stand time } \\
\text { Cognitive } \\
\text { Montreal Cognitive Assessment } \\
\text { Motor-cognitive } \\
\text { Single leg stand time with dual- } \\
\text { task } \\
\text { Other } \\
\text { UPDRS-2 (ADL) }\end{array}$ & $\begin{array}{l}\text { No adverse events } \\
\text { associated with the } \\
\text { intervention } \\
100 \% \text { adherence }{ }^{\Delta \theta} \text { in } \\
\text { both groups } \\
\text { Acceptability NR }\end{array}$ \\
\hline $\begin{array}{l}\text { Ribas } \\
2017^{132} \# \\
\text { PEDro } 7 \\
\text { Brazil }\end{array}$ & H\&Y 1-3 & $\begin{array}{l}10 \\
0 \\
10 \\
0\end{array}$ & $\begin{array}{l}\text { Nintendo Wii Fit } \\
\text { (Nintendo Inc., Japan) } \\
\text { with balance board } \\
\text { Non-immersive }\end{array}$ & $\begin{array}{l}\text { Virtual reality balance exergames from } \\
\text { a menu of } 7 \text { games } \\
\text { Conventional exercise including } \\
\text { stretching, resistance and diagonal } \\
\text { movements }\end{array}$ & $\begin{array}{l}\text { Visual and } \\
\text { auditory } \\
\text { feedback } \\
\text { Progression NR }\end{array}$ & $\begin{array}{l}30 \text { minutes } \\
2 / \text { week } \\
12 \text { weeks }\end{array}$ & $\begin{array}{l}\text { Facility } \\
\text { Unclear } \\
100 \% \\
\text { Physiotherapist } \\
\text { supervised }\end{array}$ & $\begin{array}{l}\text { Post-intervention and } 60 \text { days } \\
\text { follow up } \\
\text { Motor } \\
\text { Berg Balance Scale*b } \\
6 \text {-minute walk test distance } \\
\text { Other } \\
\text { Fatigue Severity Scale*b } \\
\text { PDQ-39 domains (mobility, ADL, } \\
\text { social well being, stigma, social } \\
\text { support, cognition, } \\
\text { communication, bodily } \\
\text { discomfort) }\end{array}$ & $\begin{array}{l}\text { No adverse events } \\
\text { associated with the } \\
\text { intervention } \\
\text { Feasibility NR } \\
\text { Acceptability NR }\end{array}$ \\
\hline $\begin{array}{l}\text { Shen } \\
2014^{133 \wedge \#} \\
\text { Shen } \\
2015^{134 \wedge} \\
\text { PEDro 7/8 } \\
\text { Hong Kong }\end{array}$ & H\&Y 2-3 & 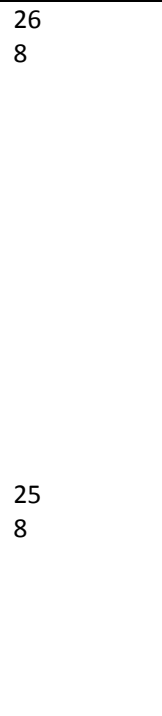 & $\begin{array}{l}\text { Computerised dancing } \\
\text { system (KSD } \\
\text { Technology Co Ltd. } \\
\text { Shenzhen, China) with } \\
\text { dance mat, light- } \\
\text { sensitive rods and } \\
\text { screen; plus Smart- } \\
\text { EquiTest Balance } \\
\text { Master with force plate } \\
\text { and screen (NeuroCom } \\
\text { International Inc, } \\
\text { Clackmas OR) } \\
\text { Non-immersive }\end{array}$ & $\begin{array}{l}\text { Technology-assisted balance exercises } \\
\text { - Facility: reaching and stepping dance } \\
\text { mat (15 minutes) and force plate step } \\
\text { amplitude ( } 15 \text { minutes) exercises; } \\
\text { responding to external perturbations } \\
\text { in } 4 \text { directions via unexpected stopping } \\
\text { and starting on a treadmill, or during } \\
\text { overground walking with perturbations } \\
\text { delivered by a therapist ( } 30 \text { minutes). } \\
\text { Home: practice of balance-demanding } \\
\text { activities, e.g. standing up from sitting, } \\
\text { turning and walking quickly with large } \\
\text { steps (20 minutes). } \\
\text { Strength exercises - Facility: lower } \\
\text { limb progressive resistance exercises, } \\
\text { stepping and walking with leg weights } \\
\text { (60 minutes). Home: stepping and } \\
\text { walking with leg weights ( } 20 \text { minutes). }\end{array}$ & $\begin{array}{l}\text { Forceplate: } \\
\text { visual KP } \\
\text { Forceplate and } \\
\text { dance mat } \\
\text { visual KR- } \\
\text { score out of } \\
100 \% \\
\text { Progression: } \\
\text { when score } \geq \\
80 \% \text {, speed } \\
\text { and/or step } \\
\text { amplitude are } \\
\text { increased, } \\
\text { stepping } \\
\text { pattern is } \\
\text { changed and/or } \\
\text { stepping over } \\
\text { an obstacle is } \\
\text { added }\end{array}$ & $\begin{array}{l}60 \text { minutes } \\
\text { facility } \\
\text { sessions } \\
3 / \text { week } \\
\text { (weeks 1-4 } \\
\text { and 9-12); } \\
+ \\
20 \text { minutes } \\
\text { home } \\
\text { sessions } \\
\text { 5/week } \\
\text { (weeks 5- } \\
\text { 8) } \\
12 \text { weeks }\end{array}$ & $\begin{array}{l}\text { Facility and } \\
\text { home } \\
\text { Facility unclear } \\
\text { Home individual } \\
\text { Facility } 100 \% \\
\text { Home } 0 \% \\
\text { Overall } 55 \% \\
\text { Physiotherapist } \\
\text { supervised }\end{array}$ & $\begin{array}{l}\text { Post intervention, } 3 \text { month and } 12 \\
\text { month follow up } \\
\text { Motor } \\
\text { Limit of stability test } \\
\text { (movement velocity and end- } \\
\text { point excursion) } \\
\text { Single leg stance time*c (3\& } 12 \\
\text { month) } \\
\text { Gait velocity (preferred speed) } \\
\text { Stride length (preferred speed) } \\
\text { *a (all time points) } \\
\text { Motor control test (speed of } \\
\text { response to backwards } \\
\text { external perturbation)*a (all time } \\
\text { points) } \\
\text { Other } \\
\text { Fall rate*a (post and } 3 \text { months) } \\
\text { Number of fallers*a (all time points) } \\
\text { Time to first fall } \\
\text { Activities-Specific Balance } \\
\text { Confidence Scale }\end{array}$ & $\begin{array}{l}\text { Safety harness used } \\
\text { during treadmill } \\
\text { perturbations } \\
\text { No adverse events } \\
\text { associated with the } \\
\text { intervention } \\
\text { Adherence } \\
\text { both groups: } \\
97 \% \text { technology group vs } \\
96 \% \text { strength group }\end{array}$ \\
\hline
\end{tabular}




\begin{tabular}{|c|c|c|c|c|c|c|c|c|c|}
\hline & \multicolumn{2}{|c|}{ Population } & \multirow{2}{*}{$\begin{array}{c}\text { Intervention } \\
\text { VR system } \\
\text { Level of immersion }\end{array}$} & \multirow[b]{2}{*}{ Training } & \multirow[b]{2}{*}{$\begin{array}{l}\text { VR Feedback } \\
\text { VR Progression }\end{array}$} & \multirow[b]{2}{*}{\begin{tabular}{l}
\multicolumn{1}{c}{ Dose } \\
minutes \\
frequency \\
weeks
\end{tabular}} & \multirow[b]{2}{*}{\begin{tabular}{l}
\multicolumn{1}{c}{ Delivery } \\
Location \\
Method \\
Supervision (\%)
\end{tabular}} & \multicolumn{2}{|c|}{ Results } \\
\hline $\begin{array}{l}\text { Author } \\
\text { PEDro Score } \\
\text { Country }\end{array}$ & $\begin{array}{l}\text { Disease } \\
\text { severity }\end{array}$ & $\begin{array}{l}\text { Initial } \\
\text { group sizes } \\
\text { Dropouts + } \\
\text { discontinue }\end{array}$ & & & & & & $\begin{array}{l}\text { Between groups comparisons } \\
\text { (significant differences shown in } \\
\text { bold) }\end{array}$ & $\begin{array}{c}\text { Safety } \\
\text { Feasibility } \\
\text { Acceptability } \\
\text { of the VR intervention }\end{array}$ \\
\hline $\begin{array}{l}\text { Shih } \\
2016^{135} \# \sim \gamma \\
\text { PEDro } 6 \\
\text { Taiwan }\end{array}$ & H\&Y 1-3 & $\begin{array}{l}11 \\
10\end{array}$ & $\begin{array}{l}\text { Kinect sensor } \\
\text { (Microsoft Corporation, } \\
\text { Redmond, WA, USA) } \\
\text { and screen } \\
\text { Non-immersive }\end{array}$ & $\begin{array}{l}\text { Virtual reality exergame balance } \\
\text { training using } 4 \text { bespoke games ( } 2 \mathrm{x} \\
\text { standing reaching tasks, } 1 \times \text { obstacle } \\
\text { avoidance task and } 1 \times \text { marching task). } \\
\text { Conventional balance training using } \\
\text { reaching, weight-shifting and } \\
\text { marching. }\end{array}$ & $\begin{array}{l}\text { Visual - full- } \\
\text { body motion via } \\
\text { avatar on } \\
\text { screen and } \\
\text { score } \\
\text { Progression: } \\
\text { increasing the } \\
\text { amplitude, } \\
\text { frequency, } \\
\text { speed, } \\
\text { complexity and } \\
\text { number of hints } \\
\end{array}$ & $\begin{array}{l}50 \text { minutes } \\
2 / \text { week } \\
8 \text { weeks }\end{array}$ & $\begin{array}{l}\text { NR } \\
\text { NR } \\
100 \% \\
\text { Therapist } \\
\text { supervised }\end{array}$ & $\begin{array}{l}\text { Post intervention } \\
\text { Motor } \\
\text { Limit of stability test } \\
\text { (directional control*, reaction } \\
\text { time, movement velocity, } \\
\text { endpoint excursion) } \\
\text { Single leg stance time } \\
\text { Berg Balance Scale } \\
\text { Timed Up and Go }\end{array}$ & $\begin{array}{l}\text { No adverse events } \\
\text { associated with the } \\
\text { intervention } \\
100 \% \text { adherence }{ }^{\otimes \varnothing} \text { in } \\
\text { participants who } \\
\text { completed the } \\
\text { intervention (10 of } 11 \text { in } \\
\text { each group) }\end{array}$ \\
\hline $\begin{array}{l}\text { Song } 2018^{136} \\
\text { PEDro } 8 \\
\text { Australia }\end{array}$ & $\begin{array}{l}\text { MDS-UPDRS } \\
\text { part III } 32 \\
\text { (12) }\end{array}$ & $\begin{array}{l}31 \\
3+6 \\
29 \\
4\end{array}$ & $\begin{array}{l}\text { Modified StepMania } \\
\text { game from Dance } \\
\text { Dance Revolution } \\
\text { Non-immersive }\end{array}$ & $\begin{array}{l}\text { Exergame dance stepping exercise } \\
\text { using a step mat and screen, with } \\
\text { cognitive load as } 3 \text { different targets } \\
\text { required } 3 \text { different motor responses. } \\
\text { Control: usual care }\end{array}$ & $\begin{array}{l}\text { Visual - word } \\
\text { (perfect, good, } \\
\text { miss)presented } \\
\text { on screen after } \\
\text { each step. } \\
\text { Numerical score } \\
\text { after each trial. } \\
\text { Progression: } \\
\text { according to } \\
\text { participant } \\
\text { performance } \\
\text { from novice, } \\
\text { easy, medium } \\
\text { to hard levels. }\end{array}$ & $\begin{array}{l}\geq 15 \\
\text { minutes } \\
3 / \text { week } \\
12 \text { weeks }\end{array}$ & $\begin{array}{l}\text { Home } \\
\text { Individual } \\
8 \% \\
\text { Physiotherapist } \\
\text { supervised }\end{array}$ & $\begin{array}{l}\text { Post intervention, } 6 \text { month follow } \\
\text { up for fall rate only } \\
\text { Motor } \\
\text { Choice stepping (reaction time, } \\
\text { movement time, total response } \\
\text { time) } \\
\text { Functional Gait Assessment } \\
\text { Hip abductor muscle power } \\
\text { Timed Up and Gos } \\
\text { Gait adaptability (velocity of } \\
\text { stride preceding obstacle, target } \\
\text { stepping accuracy) } \\
\text { Hand reaction time } \\
\text { New Freezing of gait } \\
\text { Questionnaire } \\
\text { Perception of overall change in } \\
\text { mobility* and balance } \\
\text { Cognitive } \\
\text { Montreal Cognitive Assessment } \\
\text { Trail Making Tests Part A and B } \\
\text { Other } \\
\text { Fall rate } \\
\text { Falls Efficacy scale - } \\
\text { International }\end{array}$ & $\begin{array}{l}\text { One non-injurious fall } \\
\text { during VR training } \\
\text { Two ceased training due } \\
\text { to pre-existing low back } \\
\text { pain exacerbated by } \\
\text { training } \\
88 \% \text { completing the } \\
\text { intervention progressed } \\
\text { in level of game-play } \\
86 \% \text { overall adherence }\end{array}$ \\
\hline
\end{tabular}




\begin{tabular}{|c|c|c|c|c|c|c|c|c|c|}
\hline & \multicolumn{2}{|c|}{ Population } & \multirow{2}{*}{$\begin{array}{c}\text { Intervention } \\
\text { VR system } \\
\text { Level of immersion }\end{array}$} & \multirow[b]{2}{*}{ Training } & \multirow[b]{2}{*}{$\begin{array}{l}\text { VR Feedback } \\
\text { VR Progression }\end{array}$} & \multirow[b]{2}{*}{$\begin{array}{l}\quad \text { Dose } \\
\text { minutes } \\
\text { frequency } \\
\text { weeks }\end{array}$} & \multirow[b]{2}{*}{\begin{tabular}{l}
\multicolumn{1}{c}{ Delivery } \\
Location \\
Methodv \\
Supervision (\%)
\end{tabular}} & \multicolumn{2}{|c|}{ Results } \\
\hline $\begin{array}{l}\text { Author } \\
\text { PEDro Score } \\
\text { Country }\end{array}$ & $\begin{array}{l}\text { Disease } \\
\text { severity }\end{array}$ & \begin{tabular}{l}
\multicolumn{1}{c}{ Initial } \\
group sizes \\
Dropouts + \\
discontinue
\end{tabular} & & & & & & $\begin{array}{l}\text { Between groups comparisons } \\
\text { (significant differences shown in } \\
\text { bold) }\end{array}$ & $\begin{array}{c}\text { Safety } \\
\text { Feasibility } \\
\text { Acceptability } \\
\text { of the VR intervention }\end{array}$ \\
\hline $\begin{array}{l}\text { Tollar } \\
2019^{137} \\
\text { PEDro } 6 \\
\text { Country NR }\end{array}$ & H\&Y 2-3 & $\begin{array}{l}25 \\
0 \\
25 \\
0\end{array}$ & $\begin{array}{l}\text { Kinect Xbox } 360 \\
\text { (Microsoft, Redmond, } \\
\text { WA, USA) } \\
\text { Non-immersive }\end{array}$ & $\begin{array}{l}\text { Virtual reality exergames from Kinect } \\
\text { Adventures: } 3 \text { games focusing of } \\
\text { responding quickly, reaching targets } \\
\text { with limbs and whole body, generating } \\
\text { and combining movement sequences } \\
\text { (VR) } \\
\text { Stationary cycling: Spin class, cycling at } \\
110-140 \text { bpm to music in } 5 \text {-min bouts, } \\
\text { interspersed with 1-min freewheeling. } \\
\text { (SC) } \\
\text { Control: continued usual physical } \\
\text { activity (C) }\end{array}$ & $\begin{array}{l}\text { Visual - full- } \\
\text { body motion via } \\
\text { avatar on } \\
\text { screen } \\
\text { Progression NR }\end{array}$ & $\begin{array}{l}60 \text { minutes } \\
5 / \text { week } \\
5 \text { weeks }\end{array}$ & $\begin{array}{l}\text { Facility } \\
\text { Group (4-8 } \\
\text { participants) } \\
100 \% \\
\text { Physiotherapist } \\
\text { supervised }\end{array}$ & $\begin{array}{l}\text { Post intervention } \\
\text { Motor: } \\
\text { Berg Balance Scale* (VR vs SC, } \\
\text { VR vs C, SC vs C) } \\
\text { Dynamic Gait Index* (VR vs C) } \\
6 \text { minute walk test* (VR vs C, SC } \\
\text { vs C) } \\
\text { Standing posturography* (wide } \\
\text { stance, narrow stance, tandem } \\
\text { stance) (VR vs C) } \\
\text { BESTest } \\
\text { Tinetti Assessment Tool } \\
\text { Other: } \\
\text { UPDRS-2 (ADL)* (VR vs C, SC vs } \\
\text { C) } \\
\text { Schwab \& England ADL* (VR vs } \\
\text { C) } \\
\text { Beck Depression Index* (VR vs } \\
\text { C, SC vs C) } \\
\text { PDQ-39 total + mobility } \\
\text { subscore* (VR vs C, SC vs C) } \\
\text { EuroQOL-5D* (VR vs C, SC vs C) }\end{array}$ & $\begin{array}{l}\text { No adverse events } \\
\text { associated with the } \\
\text { intervention } \\
100 \% \text { adherence }^{\otimes \varnothing}\end{array}$ \\
\hline $\begin{array}{l}\text { van den } \\
\text { Heuvel } \\
\text { 2014 } \\
\text { PEDro } 8 \\
\text { Netherlands }\end{array}$ & H\&Y 2-3 & $\begin{array}{l}17 \\
0 \\
16 \\
2\end{array}$ & $\begin{array}{l}\text { Motek Medical (Motek } \\
\text { Medical, Amsterdam, } \\
\text { The Netherlands), with } \\
\text { force plate and inertial } \\
\text { sensors } \\
\text { Non-immersive }\end{array}$ & $\begin{array}{l}\text { Virtual reality exergame balance } \\
\text { training: } 6 \text { games }(4 \times \text { leaning, } 1 \times \\
\text { stepping and } 1 \times \text { sit-to-stand) } \\
\text { Conventional balance training }\end{array}$ & $\begin{array}{l}\text { Visual feedback } \\
\text { via avatar on } \\
\text { screen } \\
\text { Points accrued } \\
\text { for faster and } \\
\text { more accurate } \\
\text { performance } \\
\text { Progression: via } \\
\text { adjustment of } \\
\text { sensitivity to } \\
\text { movement } \\
\text { along each axis } \\
\text { and speed, and } \\
\text { increase } \\
\text { duration of } \\
\text { games }\end{array}$ & $\begin{array}{l}60 \text { minutes } \\
2 / \text { week } \\
5 \text { weeks }\end{array}$ & $\begin{array}{l}\text { Facility } \\
\text { Group-worked } \\
\text { in pairs } \\
100 \% \\
\text { Physiotherapist } \\
\text { supervised }\end{array}$ & $\begin{array}{l}\text { Post intervention } \\
\text { Motor: } \\
\text { Functional Reach } \\
\text { Berg Balance Scale } \\
\text { Single leg stand time } \\
10 \mathrm{~m} \text { walk } \\
\text { Other: } \\
\text { UPDRS (total, motor subscore } \\
\text { and posture and gait subscore) } \\
\text { Falls Efficacy scale - } \\
\text { International } \\
\text { PDQ-39 } \\
\text { Hospital Anxiety and Depression } \\
\text { Scale } \\
\text { Multidimensional Fatigue } \\
\text { Inventory }\end{array}$ & $\begin{array}{l}\text { No adverse events } \\
\text { associated with the } \\
\text { intervention } \\
\text { Adherence similar in } \\
\text { each group with both } \\
\text { attending } 9(8-10) \\
\text { (median (IQR)) sessions } \\
\text { Participants with more } \\
\text { advanced disease } \\
\text { required some } \\
\text { assistance with VR } \\
\text { equipment. } \\
\text { VR training equipment } \\
\text { considered suitable for } \\
\text { use in a group setting. } \\
\text { Therapists felt } \\
\text { participants liked the } \\
\text { games and feedback } \\
\text { scores. }\end{array}$ \\
\hline
\end{tabular}




\begin{tabular}{|c|c|c|c|c|c|c|c|c|c|}
\hline & \multicolumn{2}{|c|}{ Population } & \multirow{2}{*}{$\begin{array}{c}\text { Intervention } \\
\text { VR system } \\
\text { Level of immersion }\end{array}$} & \multirow[b]{2}{*}{ Training } & \multirow[b]{2}{*}{$\begin{array}{l}\text { VR Feedback } \\
\text { VR Progression }\end{array}$} & \multirow[b]{2}{*}{\begin{tabular}{l}
\multicolumn{1}{c}{ Dose } \\
minutes \\
frequency \\
weeks
\end{tabular}} & \multirow[b]{2}{*}{\begin{tabular}{l}
\multicolumn{1}{c}{ Delivery } \\
Location \\
Method \\
Supervision (\%)
\end{tabular}} & \multicolumn{2}{|c|}{ Results } \\
\hline $\begin{array}{l}\text { Author } \\
\text { PEDro Score } \\
\text { Country }\end{array}$ & $\begin{array}{l}\text { Disease } \\
\text { severity }\end{array}$ & \begin{tabular}{l}
\multicolumn{1}{c}{ Initial } \\
group sizes \\
Dropouts + \\
discontinue
\end{tabular} & & & & & & $\begin{array}{l}\text { Between groups comparisons } \\
\text { (significant differences shown in } \\
\text { bold) }\end{array}$ & $\begin{array}{c}\text { Safety } \\
\text { Feasibility } \\
\text { Acceptability } \\
\text { of the VR intervention }\end{array}$ \\
\hline $\begin{array}{l}\text { Yang } \\
2016^{139 \wedge \# ~} \\
\text { PEDro } 7 \\
\text { Taiwan }\end{array}$ & H\&Y 2-3 & $\begin{array}{l}11 \\
1 \\
12 \\
1\end{array}$ & $\begin{array}{l}\text { Custom-made wireless } \\
\text { balance board (Cycling } \\
\text { and Health Centre of } \\
\text { Taichung, Taiwan) + 22- } \\
\text { inch touchscreen. } \\
\text { Centre of pressure } \\
\text { signal used for } \\
\text { controlling virtual } \\
\text { objects or human } \\
\text { avatar } \\
\text { Non-immersive }\end{array}$ & $\begin{array}{l}\text { Virtual reality exergame balance } \\
\text { training withbespoke games focusing } \\
\text { on static posture and dynamic weight } \\
\text { shift ( } 3 \times \text { basic, } 3 \times \text { indoor daily tasks, } 3 \\
x \text { outdoor daily tasks) } \\
\text { Conventional balance training }\end{array}$ & $\begin{array}{l}\text { Instantaneous } \\
\text { visual and } \\
\text { auditory } \\
\text { feedback. Game } \\
\text { scores. } \\
\text { Progression: } \\
\text { sensitivity of } \\
\text { balance board } \\
\text { adjusted, plus } \\
\text { manipulative } \\
\text { task and/or } \\
\text { standing on } \\
\text { foam }\end{array}$ & $\begin{array}{l}50 \text { mins } \\
2 / \text { week } \\
6 \text { weeks }\end{array}$ & $\begin{array}{l}\text { Home } \\
\text { Individual } \\
100 \% \\
\text { Physiotherapist } \\
\text { supervision }\end{array}$ & $\begin{array}{l}\text { Post intervention and } 2 \text { week } \\
\text { follow up } \\
\text { Motor: } \\
\text { Berg Balance Scale } \\
\text { Dynamic Gait Index } \\
\text { Timed Up and Go } \\
\text { UPDRS-III (motor) } \\
\text { Other: } \\
\text { PDQ-39 }\end{array}$ & $\begin{array}{l}\text { Safety NR } \\
\text { Feasibility NR } \\
1 \text { participant in the VR } \\
\text { group ceased training as } \\
\text { they preferred } \\
\text { conventional } \\
\text { physiotherapy. }\end{array}$ \\
\hline $\begin{array}{l}\text { Yen } \\
2011^{140 \wedge \sim \gamma} \\
\text { PEDro } 7 \\
\text { Taiwan }\end{array}$ & H\&Y 2-3 & $\begin{array}{l}14 \\
2 \\
\\
14 \\
2 \\
14 \\
6\end{array}$ & $\begin{array}{l}\text { Custom-made wireless } \\
\text { balance board with } \\
\text { dual-hinge tiltable foot } \\
\text { plate (multiplanar } \\
\text { movements) (Cycling } \\
\text { and Health Centre of } \\
\text { Taichung, Taiwan) + 22- } \\
\text { inch touchscreen. Signal } \\
\text { from sensor detecting } \\
\text { body weight shift used } \\
\text { to control the virtual } \\
\text { board in the VR } \\
\text { environment. } \\
\text { Non-immersive }\end{array}$ & $\begin{array}{l}\text { Virtual reality exergame balance } \\
\text { training with bespoke exercises ( } 2 x \\
\text { games focusing on weight shifting) } \\
\text { (VR) } \\
\text { Conventional balance training (B) } \\
\text { Control: No physiotherapy (C) }\end{array}$ & $\begin{array}{l}\text { Visual feedback } \\
\text { Progression: } \\
\text { decreasing } \\
\text { weight shifting } \\
\text { sensitivity and } \\
\text { using reverse } \\
\text { mode (direction } \\
\text { of weight shift } \\
\text { had opposite } \\
\text { effect on virtual } \\
\text { board in VR } \\
\text { environment }\end{array}$ & $\begin{array}{l}30 \text { mins } \\
(10 \text { min } \\
\text { warm up, } \\
20 \text { min } \\
\text { training) } \\
2 / \text { week } \\
6 \text { weeks }\end{array}$ & $\begin{array}{l}\text { Facility } \\
\text { NR } \\
100 \% \\
\text { Physiotherapist } \\
\text { supervision }\end{array}$ & $\begin{array}{l}\text { Post intervention and } 4 \text { week } \\
\text { follow up } \\
\text { Motor: } \\
\text { Sensory Organisation Test } \\
\text { Equilibrium Score } \\
\left.\text { SOT-6* (VR vs } C^{b}\right) \\
\left.\text { SOT-5* (B vs } C^{b}\right) \\
\text { SOT-1 to } 4 \\
\text { Sensory Organisation Test } \\
\text { Sensory Ratio } \\
\text { Vestibular* (B vs } C^{b} \text { ) } \\
\text { Somatosensory } \\
\text { Vision } \\
\text { preference } \\
\text { Cognitive: } \\
\text { Verbal reaction time (simple } \\
\text { subtraction after auditory cue) } \\
\text { in sitting } \\
\text { Motor-cognitive: } \\
\text { Sensory Organisation Test } \\
\text { Equilibrium Score with dual } \\
\text { task } \\
\text { SOT-6* (VR vs C } C^{b} \text { ) } \\
\left.\text { sOT-5* (B vs } C^{b}\right) \\
\text { SOT-1 to } 4 \\
\text { Sensory Organisation Test } \\
\text { Sensory Ratio with dual task } \\
\text { Vestibular* (B vs } C^{b} \text { ) } \\
\text { Somatosensory } \\
\text { Vision } \\
\text { preference } \\
\text { Verbal reaction time with a dual } \\
\text { task }\end{array}$ & $\begin{array}{l}\text { No adverse events } \\
\text { associated with the } \\
\text { intervention } \\
\text { Therapists needed to } \\
\text { assist participants to } \\
\text { prevent falls } \\
\text { Feasibility NR } \\
\text { Acceptability NR }\end{array}$ \\
\hline
\end{tabular}


Bold*: statistically significant improvement in the VR-intervention group compared with the comparison group;

Bold ${ }^{\text {: }}$ statistically significant improvement in the comparison group compared with the VR- intervention group;

$\wedge$ trial included in Dockx (2016) systematic review;

\# trial included in Wang (2019) systematic review;

$\sim$ trial included in Cano Porras (2019) systematic review;

${ }^{\gamma}$ trial included in Juras (2019) systematic review

$\checkmark$ Method: individual, group or both;

amproved at both post-test and follow-up;

Improved at post-test only;

Improved at follow-up only;

'Supervision (\%) $=\%$ of sessions supervised/sessions prescribed;

${ }^{\infty}$ Adherence $=\%$ of sessions completed $/$ sessions prescribed;

Grey shading = primary outcome/s, as identified by authors;

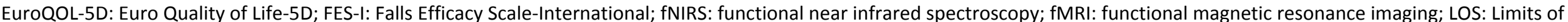

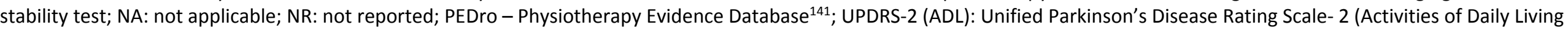
section); PDQ-39: Parkinson's disease Questionnaire-39; SPPB: Short Physical Performance Battery

\section{References}

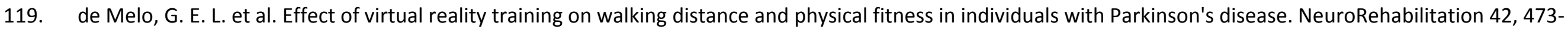
480 (2018).

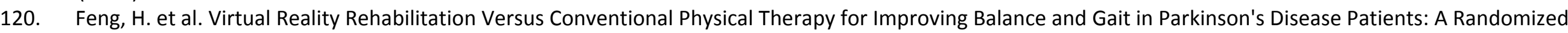
Controlled Trial. Med Sci Monit 25, 4186-4192 (2019).

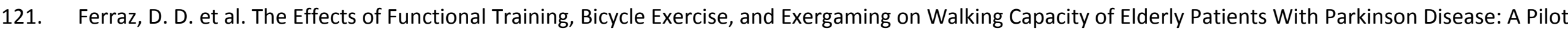
Randomized Controlled Single-blinded Trial. Arch Phys Med Rehabil 99, 826-833 (2018).

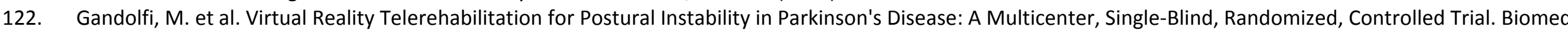
Res Int 2017, 7962826 (2017).

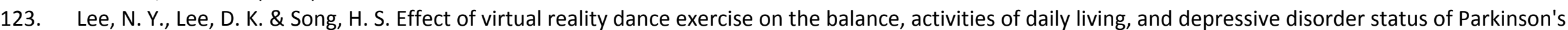
disease patients. J Phys Ther Sci 27, 145-147 (2015).

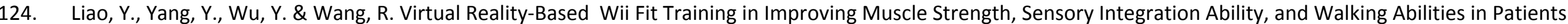
with Parkinson's Disease: A Randomized Controlled Trial. . International Journal of Gerontology 9, 190-195 (2015).

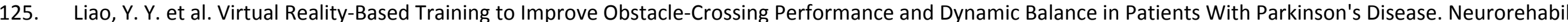
Neural Repair 29, 658-667 (2015).

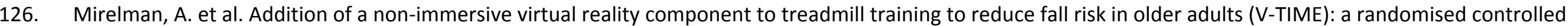
trial. Lancet 388, 1170-1182 (2016).

127. Maidan, I. et al. Disparate effects of training on brain activation in Parkinson disease. Neurology 89, 1804-1810 (2017).

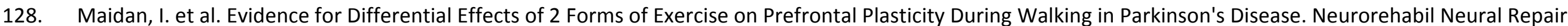
32, 200-208 (2018).

129. Dockx, K. et al. Fall-Prone Older People's Attitudes towards the Use of Virtual Reality Technology for Fall Prevention. Gerontology 63, 590-598 (2017). 


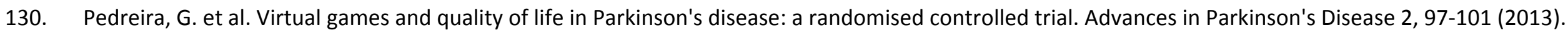

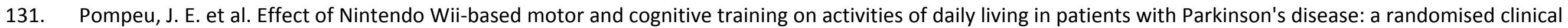
trial. Physiotherapy 98, 196-204 (2012).

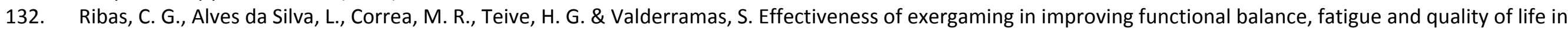
Parkinson's disease: A pilot randomized controlled trial. Parkinsonism Relat Disord 38, 13-18 (2017).

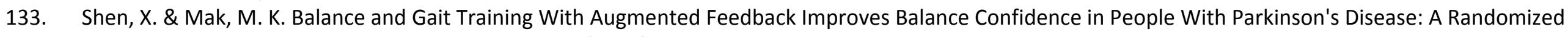
Controlled Trial. Neurorehabil Neural Repair 28, 524-535 (2014).

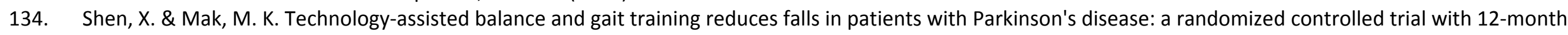
follow-up. Neurorehabil Neural Repair 29, 103-111 (2015).

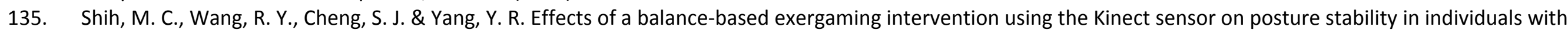
Parkinson's disease: a single-blinded randomized controlled trial. J Neuroeng Rehabil 13, 78 (2016).

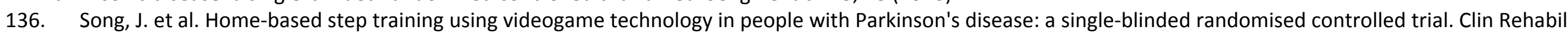
32, 299-311 (2018).

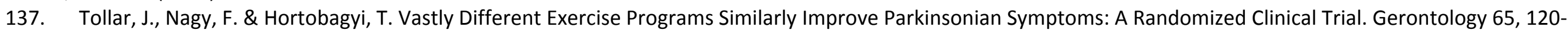
127 (2019).

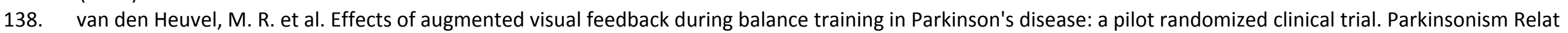
Disord 20, 1352-1358 (2014).

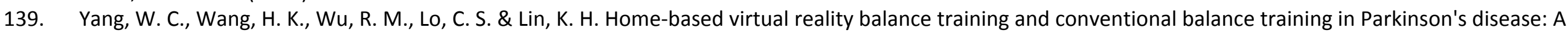
randomized controlled trial. J Formos Med Assoc 115, 734-743 (2016).

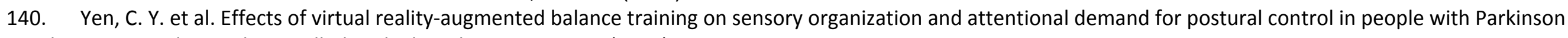
disease: a randomized controlled trial. Phys Ther 91, 862-874 (2011).

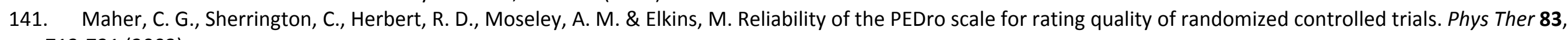
713-721 (2003). 